$10-1-2021$

\title{
Análisis del tratamiento para drogodependencias en dos instituciones de Medellín. Integración de elementos esenciales de la clínica y prácticas basadas en evidencia
}

CESAR A. GOMEZ CAGG

UNIVERSIDAD CATOLICA DE ORIENTE, cesar.gomez8062@soyuco.edu.co

Nicolás I. Uribe Aramburo NIUA

docente asociado de tiempo completo de la universidad de san buenaventura medellin colombia, nicolas.uribe@usbmed.edu.co

Follow this and additional works at: https://nsuworks.nova.edu/tqr

Digitalrt of the Clinical Psychology Commons, Quantitative, Qualitative, Comparative, and Historical

Trempons

Network

Logo

Recommended APA Citation

GOMEZ, C. A., \& Uribe Aramburo, N. I. (2021). Análisis del tratamiento para drogodependencias en dos instituciones de Medellín. Integración de elementos esenciales de la clínica y prácticas basadas en evidencia. The Qualitative Report, 26(10), 2981-3013. https://doi.org/10.46743/2160-3715/2021.5057

This Article is brought to you for free and open access by the The Qualitative Report at NSUWorks. It has been accepted for inclusion in The Qualitative Report by an authorized administrator of NSUWorks. For more information, please contact nsuworks@nova.edu. 


\title{
Análisis del tratamiento para drogodependencias en dos instituciones de Medellín. Integración de elementos esenciales de la clínica y prácticas basadas en evidencia
}

\author{
Abstract \\ Se describen y analizan los principales factores que inciden en la eficacia terapéutica del tratamiento de \\ las drogodependencias en dos instituciones en Medellín-Colombia y su relación con los protocolos de \\ atención clínica construidos a partir de los modelos conocidos como Práctica Basada en Evidencia (PBE) \\ y concretamente, Psicología Clínica Basada en la Evidencia (PsClBE). El diseño metodológico fue \\ cualitativo, se recopilaron los datos mediante la técnica de entrevistas semiestructuradas a cuatro \\ psicólogos clínicos y ocho pacientes de estas instituciones (una de modelo clínico y la otra de \\ comunidad terapéutica). El paradigma que se implementó para procesar los datos fue el interpretativo y \\ el análisis de datos incluyó la triangulación a través del software ATLAS.ti7, emergiendo siete categorías \\ de análisis. Los resultados indican que un adecuado uso; flexible y contextualizado de los manuales, \\ guías y protocolos clínicos permite reconocer la subjetividad y la importancia de la empatía, la actitud \\ clínica, entre otros factores que ayudan a establecer vínculos terapéuticos de cooperación que facilitan la \\ realización de actividades de evaluación, diagnóstico e intervención, y con ello el logro de objetivos \\ propuestos por los psicólogos clínicos que laboran en estas instituciones.

\section{Keywords} \\ psicología clínica, eficacia terapéutica, relación terapéutica, guía clínica, drogodependencia, paradigma \\ interpretativo

\section{Creative Commons License} \\ Creative \\ Commons. \\ Ahiswork is licensed under a Creative Commons Attribution-Noncommercial-Share Alike 4.0 International \\ Aicense. \\ 4.0 \\ License
}




\title{
Análisis del tratamiento para drogodependencias en dos instituciones de Medellín. Integración de elementos esenciales de la clínica y prácticas basadas en evidencia
}

\author{
César Augusto Gómez Gómez \\ Universidad Católica de Oriente, Colombia \\ Nicolás Ignacio Uribe Aramburo \\ Universidad de San Buenaventura, Colombia
}

\begin{abstract}
Se describen y analizan los principales factores que inciden en la eficacia terapéutica del tratamiento de las drogodependencias en dos instituciones en Medellín-Colombia y su relación con los protocolos de atención clínica construidos a partir de los modelos conocidos como Práctica Basada en Evidencia (PBE) y concretamente, Psicología Clínica Basada en la Evidencia (PsClBE). El diseño metodológico fue cualitativo, se recopilaron los datos mediante la técnica de entrevistas semiestructuradas a cuatro psicólogos clínicos y ocho pacientes de estas instituciones (una de modelo clínico y la otra de comunidad terapéutica). El paradigma que se implementó para procesar los datos fue el interpretativo y el análisis de datos incluyó la triangulación a través del software ATLAS.ti7, emergiendo siete categorías de análisis. Los resultados indican que un adecuado uso; flexible y contextualizado de los manuales, guías y protocolos clínicos permite reconocer la subjetividad y la importancia de la empatía, la actitud clínica, entre otros factores que ayudan a establecer vínculos terapéuticos de cooperación que facilitan la realización de actividades de evaluación, diagnóstico e intervención, y con ello el logro de objetivos propuestos por los psicólogos clínicos que laboran en estas instituciones.
\end{abstract}

Keywords: psicología clínica, eficacia terapéutica, relación terapéutica, guía clínica, drogodependencia, paradigma interpretativo

\section{Introducción}

La dependencia de sustancias psicoactivas es un fenómeno multifactorial (factores biológicos, genéticos, psicosociales, culturales y ambientales), que ha sido concebido por la ciencia médica como una enfermedad crónica y a menudo recurrente, puesto que puede ocasionar alteraciones a largo plazo en el cerebro, para la cual existen intervenciones que poseen diversos niveles de eficacia terapéutica y validez científica (Becoña \& Cortés, 2011; Castaño et al., 2014; National Institute on Drug Abuse [NIDA], 2018; Organización Mundial de la Salud [OMS], 2004). Aunque estas concepciones de las drogodependencias proceden del campo biomédico, allí se empiezan a reconocer elementos psicosociales, históricos y culturales, por lo cual, desde la psicología la dependencia a sustancias psicoactivas ha sido comprendida desde otras perspectivas (que no desconocen lo orgánico), por lo que cada escuela o corriente tiene diferentes posturas frente a la drogodependencia y las técnicas de intervención, siendo importante considerar que en los tratamientos institucionales el abordaje es interdisciplinario y por ende se utilizan equipos de profesionales de diferentes disciplinas tales como la psicología, la psiquiatría, trabajo social, entre otros. (Becoña \& Cortés, 2011). 
Respecto de la eficacia terapéutica en el tratamiento de las drogodependencias, conviene recordar la historia de las comunidades terapéutica (CT), pues éstas fueron desde sus inicios una alternativa de solución efectiva al problema de las drogodependencias, ya que los tratamientos científicos creados hasta la primera mitad del siglo $\mathrm{XX}$ eran muy pocos $\mathrm{y}$ prácticamente ineficientes, mientras que las CT's, que enfatizaban el vínculo, la cercanía, la familiaridad, la empatía, la compresión, la aceptación, la motivación, el valor del grupo y lo comunitario, mostraban más éxito. Aunque las CT's tienen fuertes raíces religiosas (su antecedente más remoto es el año 25 A.C.) y en los grupos de autoayuda, estas fueron evolucionando y teniendo en cuenta teorías y técnicas de la psiquiatría, la psicología, y otras ciencias sociales, pero conservando valores y principios que tienen que ver más con la humanidad, que con la técnica, por lo cual en la actualidad se conservan algunas de las técnicas y principios de las CT's en diferentes instituciones de rehabilitación, cuyo modelo es más científico. Goti (2003; 2009) informa que en los años 50’ y 60` la CT se expande a nivel mundial, pues la eficacia de los tratamientos científicos era de 2 a $4 \%$, mientras que la CT mostraba un 40 y $70 \%$ de éxito. Synanon fue la primera CT para drogodependientes y junto con Daytop Village fueron influyentes en el mundo. En 1956 Nyswander, demuestran que no existen evidencias de psicoterapias (tratamiento científico) exitosas que permitieran a los consumidores volver a una vida normal. Esta situación hizo que en un principio no se incluyera la psicología en el tratamiento de las CTs, inclusive, en algunos casos se consideraba contraria, fue hasta mediados de los años 80'en los que se fueron acercando las ciencias de la salud (con sus técnicas gestálticas, cognitivas, conductistas, sistémicas, etc.). Sin embargo, será en los años $90^{\prime}$ en que estos profesionales hicieron pasantías para conocer el modelo de trabajo de la CT, conociendo la autoayuda y otras de sus técnicas, creando equipos de trabajo entre los psicólogos (científicos) y los operadores de CT (adictos recuperados con rol de terapeutas). Es que en la CT el terapista, el método, el maestro, es la comunidad; es un entorno social, conformado por drogodependientes - pares-, operadores, profesionales y directivos, que sirven como modelos exitosos de vida o de cambio, que guían la recuperación. Aquí el residente (paciente) es un agente activo, el actor principal y el promotor de su propia cura.

Kooyman (1996) informa que el psiquiatra Daniel Casriel y el criminólogo Alexander Bassin, a principios de los años 60' tuvieron en cuenta las sugerencias de J. Moreno, L. Yablonsky y C. Rogers, que hacían énfasis en la persona y el vínculo con el grupo, con la comunidad; para conocer las experiencias de Synanon, aprendieran del modelo y crearan una CT en Nueva York, que permitiera conjugar los elementos no profesionales y científicos, es decir una visión más completa del tratamiento. Es así como en 1963 Casriel, Bassin, Monseñor O’Brien y algunos egresados de Synanon, entre ellos David Deitch, abren Daytop Village, en Nueva York. Al respecto un autor que reconoce el aprendizaje obtenido de las CT es Maslow (1967, citado en Kooyman 1996) quien inicialmente reportó su sorpresa por el tono de voz fuerte que a veces utilizan los operadores de CT, sin embargo, posteriormente comprendió que este brusco acto de honestidad, más que un insulto es una especie de respeto, pues una vez superado el dolor de la confrontación, se empieza a llegar a conocerse a sí mismo y a reconocer la necesidad de protección y seguridad, un sentido de pertenencia a un grupo, similar a una familia, que le haga sentir parte de él, donde se les aprecia y pueden ser tratados con respeto y estima.

Cortés, Fernández, García, Martínez, y Sierra (2018) exponen que actualmente el componente central para la intervención de las drogodependencias han sido los tratamientos psicológicos, dirigidos hacia la abstinencia, reducción del daño asociados al consumo, mantenimiento de la adherencia terapéutica, prevención de recaídas, aumento de la competencia y calidad de vida del paciente y prevención o reducción de comorbilidad psiquiátrica cuando se presenta. Estas intervenciones psicoterapéuticas evidencian altos niveles de eficacia, por lo tanto, es muy importante conocer la evidencia científica de los diferentes 
tratamientos buscando la optimización de recursos y la ética profesional, pudiendo seleccionar el tratamiento que más beneficie al paciente, más allá de las preferencias y/o prejuicios personales.

Ahora bien, en el marco del tratamiento de las drogodependencias actualmente se usan predominantemente las terapias y técnicas basadas en la evidencia científica. Las Prácticas Basadas en Evidencia (PBE) inician en la medicina (Medicina Basada en la Evidencia o MBE), Daset y Cracco (2013), siguiendo los trabajos de Haynes, Sackett, Gray, Cook, y Guyatt (1996) y Sackett, Rosenberg, Gray, Haynes, y Richardson (1996) proponen que los antecedentes de PBE encuentra sus raíces en la MBE, y Lam, Pérez, Hernández, y Milanés (2002) reportan que la MBE hace alusión a la actualización en las mejores evidencias científicas disponibles para la toma de decisiones sobre el cuidado de los pacientes, mediante un método organizado que resuelve las dudas de la práctica clínica, con información científica válida. Aunque sus orígenes filosóficos fueron a finales del siglo XIX en París, las MBE, se inician en 1988 en la universidad de Mc Máster en Canadá y empieza a reconocerse en todo el mundo a partir de los años 90 .

Las PBE tienen tres pilares (a) Fundamento empírico, (b) Se tiene en cuenta el contexto con sus costumbres y tradiciones, y (c) la experiencia del profesional. A pesar de que estas prácticas fueron reconocidas por la APA en el 2006, desde los años 90' se venían haciendo trabajos con las Psicoterapias con Apoyo Empírico (PAE), que fueron evolucionando como respuesta ante las críticas por su tendencia en exceso hacia la evidencia, dejando de lado los aspectos contextuales. En la actualidad hay una tendencia creciente de realizar intervenciones con evidencia, que particularmente en psicología se conoce como Práctica Psicológica Basada en Evidencia (PPBE). Ahora bien, los expertos en el tema explican que las PPBE no se deben usar como un protocolo aplicado de manera rígida en el paso a paso (a "raja tabla"), pues debe realizarse una adaptación de los modelos terapéuticos a las necesidades de los usuarios. (Martínez-Taboas, 2014). La psicología clínica basada en la evidencia (PsClBE) es un estándar que se usa en la práctica clínica, buscando integrar los resultados de investigaciones recientes, la experiencia en el quehacer clínico y las características del contexto de la población a la cual se dirigen (American Psychological Association [APA], 2006; Callahan et al., 2013; Daset \& Cracco, 2013; DuPont et al., 2015; Quant \& Trujillo, 2014).

Por lo anterior algunos autores consideran que estos modelos clínicos representan un punto de referencia confiable para los profesionales de psicología clínica que trabajan en salud mental y una posibilidad de tratamiento exitoso. Así, algunos autores explican que la mera aplicación de la técnica basada en la evidencia no es suficiente para el éxito terapéutico, puesto que es importante tener presente la relación terapéutica, por lo cual subrayan la necesidad de proponer nuevas estrategias de evaluación e intervención, usando metodologías rigurosas que permiten una integración entre ciencia y profesión, siendo investigadores en el ejercicio y prácticos en la investigación (Hayes, et. al, 1999; Hayes et al., 2013; Lowman 2012; Quant \& Trujillo, 2014). Por ello, es importante tener presente el hecho de que aun cuando existan tratamientos estandarizados que han sido validados empíricamente, ello no impide ajustar los procedimientos a las realidades de cada paciente (Allen \& Kaden, 1995; Echeburúa et al., 2010). Como consecuencia de lo anterior, actualmente existe un progreso significativo en los terapeutas de drogodependencias hacia la adopción de tratamientos basados en evidencia (Martínez \& Medina-Mora, 2013) y una tendencia creciente en estos profesionales a ceñirse a los elementos técnicos de la psicoterapia, más allá del abordaje del vínculo (Casari et al., 2017).

Sin embargo, en el contexto de las drogodependencias algunos autores resaltan que la relación terapéutica es la base sobre la que se establece el proceso terapéutico y la posibilidad del cambio, en este sentido reconoce que la diversidad de modelos y enfoques con sus distintas técnicas deben estar al servicio de las personas y no a la inversa (Chacón, 2016). Según, Pacheco, Ayme, y Martínez (2013) los factores relacionados con el éxito del tratamiento de las 
adicciones serían los conocimientos del modelo de atención (y las teorías psicológicas), la creencia en las posibilidades de cambio de la población, la empatía, entre otros.

Respecto de la importancia de la empatía, Lambert y Barley (2001) concluyen que es una obligación de los clínicos no olvidar que décadas de investigación han mostrado que la empatía en la relación terapéutica está correlacionada con los resultados positivos, y no solo el seguimiento estricto de las técnicas estandarizadas, lo cual se explica por el hecho de que el componente primario promotor de la cura es la relación terapéutica y ésta proporciona el contexto para que las técnicas específicas ejerzan su influencia. Tal como lo muestra la expresión de Alexander \& French (1965) al concebir la clínica como una "experiencia emocional correctiva." Así mismo, otros autores concluyen que la empatía favorece el establecimiento de la relación positiva entre terapeuta y paciente, y que es indispensable para el éxito terapéutico, pues esta habilidad del clínico facilita que el paciente sienta confianza para exteriorizar sus pensamientos y sentimientos, es decir, para brindar información requerida en la evaluación y para hacer una catarsis durante las sesiones de psicoterapia (Etchevers et al., 2014).

Mayor, Noval, Cepedello, y Prieto (2018) Recomienda que al momento de realizar la evaluación clínica en drogodependencias y diligenciamiento de la historia clínica, que es indispensable en el tratamiento, a parte de los conocimientos teóricos, el manejo en guías clínicas, el espacio en el que se desarrolla, es de vital importancia que el profesional desarrolle la entrevista clínica con actitud empática, en un clima de confianza, escucha activa, comprensión y colaboración, libre de críticas, moralizaciones, órdenes, amenazas, ridiculización y confrontación, manteniendo flexibilidad entre directividad/no directividad, es decir, permitiendo que el paciente sea amplio en su expresión en los primeros momentos para después dirigir la entrevista, esto condicionará los otros momentos del tratamiento, siendo éste primer contacto el inicio de la relación interpersonal entre profesional y paciente, y el insumo para realizar la evaluación, el diagnostico, plan de tratamiento y pronóstico. En este sentido la entrevista clínica en el diligenciamiento de la historia clínica es el mejor instrumento de evaluación clínica que complementa los instrumentos estandarizados, tal como se mostrará en el análisis de los resultados de esta investigación.

Desde las diferentes orientaciones teóricas se ha investigado y construido diferentes definiciones y formas de realizar la clínica psicológica de forma eficaz, siendo un común acuerdo la importancia otorgada a las actitudes y aptitudes que debe tener el terapeuta, entre las cuales destacan la empatía (capacidad del terapeuta de ponerse en el lugar del paciente), pues esta capacidad permite reconocer emociones y sentimientos para poder comprender al paciente. Por otro lado, se ha demostrado que si hay mayor satisfacción del paciente en la relación terapéutica habrá más adherencia al tratamiento y menor probabilidad de deserción. Otro de los elementos que destacan los psicólogos clínicos es la capacidad de ser flexibles, es decir, la capacidad que tienen para ajustar su estilo de intervención a las particularidades de cada persona. Así mismo, los clínicos demuestran capacidad para dirigir o conducir el proceso en cualquier momento (entrevista de evaluación, de devolución, entre otros). De otro lado, los expertos también reconocen la importancia de la actitud docente del terapeuta, quien con sus conocimientos y experiencias puede aportar al aprendizaje del paciente. Las propuestas actuales de psicoterapia amplían el concepto de relación terapéutica, puesto que ahora se le da un rol importante al paciente como co-constructor del proceso, ya que, anteriormente el terapeuta era el responsable del cambio y el paciente el del no cambio, por lo que algunos autores afirman que en la actualidad se le da mayor importancia a la ética y al uso del lenguaje que a la técnica (Arango \& Moreno, 2009; Cormier \& Cormier, 1994; Corominas \& García, 2014; Durán et al., 2007; Fiorini, 1992; Wilson \& O`Leary, 1980).

Echeburúa, Salaberría, de Corral, y Polo (2010) también reconocen que el éxito del terapeuta no solo se reduce al dominio de la teoría o a la experiencia previa, siendo importante 
el trabajo en equipo, la motivación por la profesión, y en especial a la inteligencia emocional, la autoestima y las relaciones interpersonales, que se convierten en herramientas indispensables en el desempeño adecuado en la psicología clínica.

Otro aspecto esencial de la psicología clínica es el reconocimiento de la subjetividad, a partir del método clínico (Braunstein et al., 2013), propuesta promovida por Canguilhem (2014) como ciencia de la subjetividad, en la cual, la verdad y la realidad del mundo no es concebida con la percepción de la razón matemática y mecánica, sino, por el sujeto de la experiencia. Al respecto, Gadamer (2017) propone que el conocimiento del hombre es subjetivo, éste está sumido en conocimientos provenientes de la tradición cultural, la literatura, las artes en general, la histografía y demás ciencias históricas.

En esta misma línea, Yalom (2010) plantea que cuando se utiliza el mismo diseño para entender a todas las personas, se pasa por alto la experiencia individual de la persona, es decir su condición única e irrepetible. De Castro y García (2017) afirman que antes que explicar el comportamiento y buscar la validez cuantitativa de la experiencia humana, se debe comprender la individualidad de cada persona, para evitar ajustar a cada ser humano a nuestra propia concepción del mundo. Por otra parte, Laing (2015) propone que se debe pensar al hombre de manera individual, como un organismo, pero también debe ser reconocido como una persona en la relación con el otro.

Desde un enfoque humanista, Perls (2016) expone apoyado en la psicología de la Gestalt alemana, que el campo de la percepción humana se da como un proceso de totalidades significativas, en la cual un elemento seleccionado de los muchos presentes hace figura, mientas los demás pasan al fondo, básicamente este proceso se da cuando hay interés. Esta organización de percepciones, hechos, comportamientos y fenómenos, que cada persona hace, es lo que define y le da su significado específico y particular. Es así como el hombre es un ambiente como individuo y como ser social, formando parte del campo organismo/ambiente, en el que cada cual tiene su carácter particular por la relación que establece consigo mismo, con el otro y con el todo. Por su parte Rogers (2010), reconoce que el hombre vive en su propio mundo personal, es por ello que, para trabajar la subjetividad humana, el psicoterapeuta debe hacer esfuerzos por entrar en el mundo subjetivo del cliente. Así mismo, según Piaget (1983) El sujeto construye constantemente el conocimiento del mundo externo; desde el aspecto biológico por intercambio entre el organismo y el medio ambiente, y desde el cognoscitivo por la relación que existe entre el pensamiento y el objeto, por lo tanto, el conocimiento no es una copia del objeto, ni la consciencia de formas que están predeterminadas en el sujeto. Para Bruner (2009) el reconocimiento de la subjetividad es indispensable en la intervención en psicología clínica, pues cada persona es y crea mundos diferentes. Para Beck, Rusch, Shaw, y Emery (2012) La manera que tiene una persona de evaluar una situación, se percibe en sus cogniciones, es decir, pensamientos e imágenes visuales, éstas constituyen la "corriente de la consciencia" o campo fenoménico, que muestra la configuración que tiene de sí misma, su mundo, su pasado y su futuro. A partir de ahí, la terapia cognitiva usa las técnicas de tratamiento específicas, manejadas de un modo lógico, planificado y adaptado a la individualidad de cada paciente. Lacan (2009) propone que el psicoanálisis está supeditado a la particularidad del sujeto, y hace referencia a Freud (2007), cuando éste afirma que ésta disciplina debe ponerse en tela de juicio en el análisis del caso a caso. Según Winnicott (2013) la realidad psíquica es personal e interior y se forma en el territorio del desarrollo y en la experiencia individual, que se relaciona con la realidad exterior o compartida.

Por otro lado, Linn y Garsken (1993) desde un enfoque integrativo, concluyen que muchas psicoterapias son efectivas y que en términos de eficacia parecen ser más parecidas que diferentes, y los efectos positivos obedecen a factores comunes que se comparten más que a técnicas específicas. Las psicoterapias realizan acciones similares por caminos aparentemente únicos. Para que la psicoterapia produzca resultados (logro de objetivos), son necesarios los 
siguientes mecanismos de cambio: (a) la relación terapeuta-paciente debe ser promovida y consolidada, el paciente es activo para el cambio de conducta, en un proceso colaborativo al psicoterapeuta; (b) el psicoterapeuta genera y sostiene la expectativa de proporcionar la ayuda al paciente, generándole apoyo, valor y confianza, además de la seguridad de tener un soporte teórico para entenderlo; aumentando así la motivación; (c) se le proporciona la posibilidad al paciente de obtener un sentido de autodominio y autoeficacia; el autocontrol percibido, hace que la percepción de incompetencia e indefensión sea suplida; (d) se proporciona al paciente oportunidades nuevas para aprender diferentes formas de pensar, sentir y actuar, por medio de técnicas fundamentadas desde la teoría, ésta experiencia terapéutica le da al paciente un sentido de domino; (e) se activan emociones intensas, esta situación hace que se desarrolle más la relación terapéutica, ya que el paciente se acerca más al psicoterapeuta, mediante técnicas se le demuestra que las emociones evitadas pueden afrontarse y dominarse, se aumenta la autoestima y seguridad en sí mismo; (f) se brinda al paciente diferentes oportunidades para que practique nuevos comportamientos y afiance las ganancias terapéuticas. Aunque estos mecanismos ocurren en todas las psicoterapias, varía el énfasis en cada uno de ellos de acuerdo con el enfoque.

En síntesis, en la psicología clínica se han identificado diversos factores que influyen en el logro de los objetivos terapéuticos, entre los cuales se destaca la subjetividad que se pone en acción en la relación o vinculo terapéutico, en la interacción entre el paciente y el terapeuta en el contexto de la psicoterapia, razón por la cual este último debe crear condiciones que promuevan el establecimiento de esta relación. En ese orden de ideas, el estilo de relación interpersonal con los pacientes se ha caracterizado por la empatía, para que el paciente desarrolle confianza hacia el terapeuta y por ende coopere con el proceso clínico de evaluación, diagnostico e intervención. Para ello, se requiere que en el psicoterapeuta exista la disposición interna de ayudar a los demás con sus problemas o patologías, lo que ha sido denominado una actitud clínica (Brenstein \& Nietzel, 2011; Resnick, 1991; Rey \& Guerrero, 2012; Trull \& Phares, 2003).

En cuanto a las disposiciones legales, el ministerio de salud de Colombia y Colegio Colombiano de Psicólogos (2014) define el perfil de competencias del psicólogo en Colombia, en el contexto de la salud, allí describen las competencias transversales que tiene que ver con la formación científica, entre las cuales enfatizan el conocimiento de las prácticas basadas en la evidencia, pero también el respeto por la dignidad de las personas y comunidades, así como la importancia de las relaciones interpersonales e interdisciplinares, el conocimiento que tiene el clínico del contexto y cultura, pues ello permite que las acciones de los profesionales estén en coherencia con las necesidades de la población colombiana, respetando su diversidad, la subjetividad y las diferencias contextuales, lo cual es acorde con los resultados de investigaciones recientes que evidencian la importancia de la contextualización a la población objeto de intervención (Ediomo-Ubong \& Gboyega, 2019; Zhang et al., 2017) Es por ello que el MINSALUD, en convenio con la Oficina de las Naciones Unidas Contra la Droga y el Delito (UNODC), construyen El Modelo De Atención Integral Para Trastornos Por Uso De Sustancias Psicoactivas En Colombia (2016), tomando como principal referencia tratamientos basados en la evidencia científica acorde al contexto colombiano, el cual incluye aspectos espirituales y religiosos propios de la idiosincrasia de cada cultura o pueblo (Hai et al., 2019). En éste se explican generalidades de las drogodependencias, definiciones, historia, modelos, así como recomendaciones para el diseño de planes de tratamiento de consumidores de sustancias psicoactivas (SPA) y guías de práctica clínica seleccionadas para el tratamiento del SPA, siendo notable que solo en la sección V se enuncia brevemente el tema de la relación terapéutica.

Teniendo en cuenta este contexto, en ésta investigación se analizan factores que inciden en el tratamiento de las drogodependencias, específicamente las habilidades, capacidades y/o 
competencias clínicas que debe tener el psicólogo y la forman como éste las articula con el uso de los manuales, guías y protocolos basados en la evidencia científica, para lo cual la investigación identifica y describe las prácticas psicoterapéuticas usadas por psicólogos clínicos en el tratamiento de las drogodependencias en la ciudad de Medellín - Colombia, en modalidad internado, en dos instituciones, una de modelo clínico y otra de modelo de comunidad terapéutica.

Los investigadores, desde un enfoque cualitativo, hemos mostrado sensibilidad e interés por el fenómeno de la drogodependencia y la psicología clínica; particularmente los aspectos esenciales como: actitud clínica, rapport, empatía y aceptación incondicional, y la inquietud y expectativa por los manuales, guías y protocolos basados en evidencia, producto de más de una década de trabajo de psicoterapia con este tipo de población en modalidad interna y de consulta externa. Además, en el caso de César Gómez, también ha sido director clínico y coordinador de sede en dos Centros de Atención en Drogadicción (CAD) en el modelo de Comunidad Terapéutica. Además, ambos investigadores se dedican a la docencia universitaria, la investigación y la asesoría de prácticas profesionales. En este contexto decidimos emprender esta investigación con el fin de aportar en la construcción del conocimiento en este tema que tiene un amplio camino por recorrer, esperando que los lectores puedan utilizar los conocimientos que se presentan en este artículo para repensar y rediseñar sus propios programas, y, por ende, la prestación de mejores servicios en los que la esencia de la clínica no sea eclipsada por la tendencia actual a ceñirse ciegamente a los aspectos legales y cientificistas.

\section{Metodología}

El diseño fue cualitativo debido a que este permite explorar fenómenos poco estudiados (alcance descriptivo), como es el caso de los factores que inciden en el tratamiento institucional de las drogodependencias en Medellín Colombia, pero además se escogió este diseño porque permite conocer la subjetividad/intersubjetividad de los actores de los fenómenos estudiados, en este caso, la percepción de cuatro psicólogos clínicos y ocho pacientes de dos instituciones de la ciudad, lo que permitió conocer estas experiencias institucionales desde una fuente primaria.

Se utilizó la entrevista semiestructurada, de tipo cualitativo, ya que ésta es más flexible y permite hacer una construcción en conjunto de significados frente a una respectiva temática (Hernández et al., 2014; Janesick, 1998). Se diseñaron dos guías de entrevista (Anexos 1 y 2), cuyos ítems fueron construidos a partir de la revisión bibliográfica efectuada mediante la técnica de revisión documental, desde la cual se crearon los conceptos sensibilizadores que hacen referencia a factores que están asociados a la eficacia de los tratamientos para drogodependencias, y que posteriormente permitieron crear las categorías de análisis. El instrumento fue sometido a una prueba piloto en una de las instituciones participantes, confirmando su pertinencia.

Para la revisión de los documentos se ingresaron palabras claves (drogodependencia, adicciones, tratamiento, comunidad terapéutica, relación terapéutica, terapias psicológicas con evidencia científica, entre otras) en los descriptores de las principales bases de datos de las diversas universidades de la ciudad y de la internet, de modo que posteriormente se seleccionarían las referencias bibliográficas que brindan información sobre nuestro objeto de estudio, las cuales fueron revisadas para extraer información específica que fue consignada en fichas de lectura y bibliográficas, para organizar los datos recopilados.

Debido a que en estas instituciones el equipo interdisciplinario suele ser pequeño (aproximadamente diez profesionales, entre tres y cinco psicólogos), y considerando que es un estudio cualitativo, no se eligió una muestra representativa del universo estudiado y por el contario se escogió una unidad de análisis significativa a través de la estrategia de muestreo 
por conveniencia de los investigadores. Utilizando la técnica de bola de nieve los investigadores contactaron a algunos psicólogos que laboran en instituciones que ofrecen atención residencial no hospitalaria para la drogodependencia, una de modelo clínico y otra de modelo de comunidad terapéutica, los cuales actuaron como informantes claves y "porteros" que permitieron el acceso a las instituciones (directivos) y a otros profesionales.

En total participaron doce sujetos, once hombres y una mujer, seis por cada institución distribuidos así, dos psicólogos clínicos y cuatro pacientes; dos por cada profesional a cargo de los casos. El tamaño de la muestra estuvo determinado por la accesibilidad de los directivos, de modo que para realizar las entrevistas se evitara alterar las dinámicas de trabajo internas, con los profesionales y pacientes, quienes tienen un cronograma de actividades preestablecido. Además, la cantidad de pacientes de estas instituciones es variable, depende de la demanda externa. Los criterios de inclusión y exclusión fueron los siguientes: (1) ser mayor de edad, (2) tener experiencia de trabajo en instituciones que prestan servicios a población consumidora de drogas, mínimo tres meses, (3) ser paciente de estas instituciones, tres meses de experiencia institucional, y (4) participar voluntariamente en la investigación. Se practicaron doce entrevistas en total, entre los meses de agosto y septiembre del año 2019, en los consultorios de los profesionales, las cuales tuvieron una duración variable entre 20 y 90 minutos. Se usó grabadora para registrar las respuestas.

En cuanto a los aspectos éticos se tuvieron en cuenta los riesgos previstos y previsibles que podría generar la investigación, por lo que se sometieron los formatos de guía de entrevista a una revisión y aprobación por parte del comité de bioética de la Universidad de San Buenaventura, sede Medellín, el cual determinó que el nivel de riesgo es nulo, mediante el certificado expedido el 28 de agosto de 2019. En el momento de realizar las entrevistas se les explicó a los participantes estos aspectos éticos y todos aceptaron voluntariamente hacer parte de la investigación, por lo cual se diligenciaron los respectivos consentimientos informados. En el caso de los documentos, también se siguieron los protocolos éticos para respetar los derechos de autor, evitando el plagio intelectual. En síntesis, se tuvieron en cuenta las disposiciones legales; cumpliendo con todos los protocolos éticos de la Declaración de Helsinki 1975, así como con los lineamientos éticos de la Resolución 8430 de 1993 del Ministerio de Salud de Colombia.

Luego de que se transcribieran las entrevistas realizadas con psicólogos y pacientes, se procedió a ingresar estos datos en el Software ATLAS.ti7, para realizar el procedimiento de triangulación, que permite conocer y contrastar las semejanzas y diferencias en las respuestas de los participantes, para conocer aspectos subjetivos e intersubjetivos acerca del objeto de estudio. Luego se revisaron una a una las respuestas de los entrevistados, se crearon categorías de análisis a partir de la agrupación de temáticas comunes en los sujetos, asignando códigos a los conceptos sensibilizadores que se habían creado al hacer la revisión documental.

\section{Resultados}

Las categorías que emergieron en el proceso fueron siete, algunas de las cuales contienen subcategorías, estas son: Categoría uno: concepciones de la clínica; Categoría dos: importancia y funciones de la psicología en el proceso: Categoría tres: perfil del psicólogo clínico en el contexto de las drogodependencias. subcategoría: 3.1. Formación en psicología clínica; 3.2. Características positivas del terapeuta; y 3.3. Actitud clínica. Categoría cuatro: concepciones de las drogodependencias. Categoría cinco: competencias del psicólogo, Subcategorías; 5.1. Empatía (sensibilidad y manejo de la autoridad); 5.2. Directividad/No directividad terapéutica; y 5.3. Raport, aceptación incondicional, profesionalismo y neutralidad. Categoría seis: estrategias clínicas: subcategorías; 6.1. Relación terapéutica; 6.2. Interpretación o devolución; 6.3. Tranquilidad; 6.4. Confianza; 6.5. Alianza terapéutica; 6.6. 
Desahogo o catarsis; 6.7. Comunicación contextualizada; 6.8. Motivación y Participación del paciente; 6.9 Apertura al cambio; 6.10. Transferencia.; 6.11. Evaluación y Diagnostico; 6.12. Proceso por etapas; 6.13. Psicoeducación; 6.14. Adherencia y Aprovechamiento del tratamiento; 6.15. Reconocimiento de la subjetividad del paciente y uso Dialéctica; 6.16. Logros terapéuticos; y 6.17. Reinserción sociolaboral y prevención de recaídas. Categoría siete: uso de los manuales, protocolos y guías clínicas basadas en la evidencia científica (PBE).

\section{Discusión}

La categoría uno: concepciones de la clínica; muestra que los psicólogos que laboran en estas instituciones poseen una concepción similar del trabajo clínico, en síntesis, la conciben como una relación terapéutica, caracterizada por la empatía, el respeto por el otro y su subjetividad, entre otros factores, evidenciando que el espacio clínico es considerado como el encuentro de dos personas en relación, enfatizando la importancia de la empatía, la motivación y el encuadre para que se pueda crear la relación y logre ser un espacio de reconocimiento del paciente como un ser integral, veamos (P2MC) ${ }^{1}$ : "es la esencia propia de la psicología, es la razón de ser, no dedicarse sólo y exclusivamente a los procesos mentales, tiene que ir mucho más allá, es entender una parte integral, es interesarse propiamente por la esencia y por la psiquis, a veces uno termina como un poquito obligado a trabajar las guías," así mismo, otro clínico dice que (P1MC): "si no hay empatía con el paciente, no se puede hacer nada, ahí es donde parte una entrevista o diagnóstico." Como puede colegirse, estos psicólogos concuerdan con las concepciones acerca del trabajo clínico que se revisaron en la introducción, según las cuales, la relación terapéutica es parte fundamental del trabajo clínico, que incluye el adecuado uso de las técnicas y los protocolos (Brenstein \& Nietzel, 2011; Freud, 2007; Lacan, 2009; Lambert \& Barley, 2001; Mayor et al., 2018; Pacheco et al., 2013; Rogers, 2010)

La categoría dos: importancia y funciones de la psicología en el proceso: revela la importancia de la intervención psicológica al interior de los equipos interdisciplinarios, reconociendo su función específica en el logro de los objetivos terapéuticos, mediante estrategias como la introspección, el insight, la catarsis y el autocuestionamiento, ilustrando que todos los entrevistados reconocen que el cambio no obedece a la acción de un solo profesional o de una sola disciplina, sino que es producto del trabajo de los equipos interdisciplinarios, razón por la cual, consideran que la psicología clínica es indispensable, reconociendo que cada disciplina aporta conocimientos específicos que deben ser reconocidos y valorados sin establecer jerarquías. Así, por ejemplo, un profesional informa que estos equipos serían como: (P1MC): "una mesa de cuatro patas, donde de un lado está el psicólogo, al otro lado está el pedagogo, al otro lado el médico y al otro lado el profesional en familia, y si uno de ellos llega a faltar, entonces esa mesa va a quedar coja, entonces dentro de este tipo de tratamientos hace falta el psicólogo, cualquiera de esos cuatro es esenciales dentro de estos tratamientos."

Sin embargo, resaltan que el psicólogo debe ser activo dentro de estos equipos (P2MC): "el psicólogo en la clínica debe tener voz y voto." Además, reconocen que la psicología clínica permea todo el proceso, complementando las actividades grupales, pues es (P1MCT): "transversal a todo el proceso de la psicología, la cita pues psicológica, y de ahí también van haciendo pues un acompañamiento desde lo que él va a trabajar en lo grupal," tal como lo

\footnotetext{
${ }^{1}$ Psicólogo 1 Modelo Clínico (P1MC), Psicólogo 2 Modelo Clínico (P2MC), Psicóloga 1 Modelo Comunidad Terapéutica (P1MCT), Psicólogo 2 Modelo Comunidad Terapéutica (P2MCT), Paciente 1 Modelo Clínico (Pa1MC), Paciente 2 Modelo Clínico (Pa2MC), Paciente 3 Modelo Clínico (Pa3MC), Paciente 4 Modelo Clínico (Pa4MC), Paciente 1 Modelo Comunidad Terapéutica (Pa1MCT), Paciente 2 Modelo Comunidad Terapéutica (Pa2MCT), Paciente 3 Modelo Comunidad Terapéutica (Pa3MCT), Paciente 4 Modelo Comunidad Terapéutica (Pa4MCT).
} 
sugieren los expertos en el tema cuando recalcan la incidencia de la psicología clínica en la eficacia del tratamiento interdisciplinario (Becoña \& Cortés, 2011; Cortés et al., 2018; Goti, 2009; Kooyman, 1996; OMS, 2004; NIDA, 2018). Al respecto los propios pacientes corroboran la importancia de la intervención psicológica en el proceso (Pa4MCT): "Ha sido de gran ayuda y me ha enseñado mucho," o también que (Pa2MC): "el proceso sin la parte psicológica no funcionaría, pues sería como un zapato, sin cordón, o sea no habría como equilibrio para caminar," metáfora de un paciente que ejerce la profesión de zapatero la cual ilustra bastante bien el lugar de la psicología dentro del proceso.

Ahora bien, además de la importancia de la posición activa del psicólogo y del paciente, reportan también que la incidencia de la psicología clínica en el cambio del paciente implica que los psicólogos asumen una posición activa en la relación terapéutica promoviendo el logro de objetivos, referidos a cambios comportamentales y psicológicos que incluirían una modificación en los patrones de consumo de sustancias, así como la adquisición de nuevos hábitos de estilos de vida más saludables y funcionales, entre otros, como expone uno de los clínicos (P2MC): "los objetivos terapéuticos deben estar muy claros en el paciente, el psicólogo debe orientar todas sus intervenciones al logro de los objetivos que algún día se propusieron."

Como puede verse, los clínicos deben adoptar posturas activas que permiten la eliminación rápida del síntoma, según el modelo institucional del tratamiento de drogodependencias, hallazgo que corrobora los resultados de las investigaciones que se revisaron sobre el tema (Becoña \& Cortés, 2011; Corominas \& García, 2014; Goti, 2009; Kooyman, 1996; Linn \& Garsken, 1993; Pacheco et al., 2013).

Así mismo, es importante promover la capacidad de introspección del paciente debido a que según un psicoterapeuta el espacio clínico debe brindar (P2MCT): "la oportunidad de introyectar esos contenidos y aplicarlos, inspeccionar su propia vida y empezar a modificar cosas." Por último, es necesario promover la expresión emocional, ya que los psicólogos (P2MC): "trabajamos lo que es toda esa parte de las emociones, los sentimientos y todo lo que siente el paciente." Aquí se manifiesta claramente la necesidad de una postura activa del paciente, tal como lo sugieren clínicos expertos (Arango \& Moreno 2009; Brenstein \& Nietzel, 2011; Bruner, 2009; Corominas \& García, 2014; Freud, 2007; Goti, 2009; Kooyman, 1996; Linn \& Garsken, 1993; Pacheco et al., 2013; Rogers, 2010; Yalom, 2010). Así por ejemplo, uno de los pacientes comenta que ha (Pa1MCT): "podido valorar que si traía un problema y eso me [Le] ha abierto la mente a trabajar en esos asuntos," es decir, la introspección le permitió: (Pa4MCT): "reconocer el problema que yo tengo, desde la adicción," para después hacer un análisis con el psicoterapeuta que promueve la reflexión interna y facilita el insight, aspecto fundamental para el logro de objetivos, ya que promueve el autocuestionamiento del paciente, tal como lo corrobora uno de ellos cuando dice que (Pa2MCT): " ya uno le echa cabeza y le ayuda a uno mucho eso, me toca los puntos que yo si siento que tengo que transformar," de modo que el autocuestionamiento le ha permitido (Pa4MCT): "aprender a aceptar mi problema." Por último, la introspección también involucra aspectos del pasado, puesto que según uno de los pacientes, en el proceso: (Pa2MC): "empezamos a mirar hacia el pasado mío, hemos tratado de detectar que pudo haber pasado desde allá." En resumen, la relación terapéutica que favorece la introspección también promueve en los pacientes la apertura al cambio, veamos (Pa4MCT): "a veces no tenía ni confianza de contárselo a mi familia, con el psicólogo, he tenido la experiencia y la oportunidad," lo que se traduce en un mayor compromiso del paciente, ya que les otorga (Pa4MCT): "disposición para aprender, para aceptarme que tengo un problema, y que lo quiero cambiar."

La categoría tres: perfil del psicólogo clínico en el contexto de las drogodependencias, en esta categoría se describe la titulación académica y la experiencia laboral, así como la orientación teórica de estos psicólogos, esta incluye la subcategoría: 3.1. Formación en psicología clínica; 3.2. Características positivas del psicoterapeuta; y 3.3. Actitud clínica. 
Respecto a la subcategoría 3.1. todos los entrevistados concuerdan en que la experiencia del pregrado es básica (cursos de psicología clínica y escuelas o corrientes psicológicas; psicodinámica, humanista y cognitivo conductual), evidenciando que no recibieron una formación específica sobre drogodependencias en el pregrado y solo hicieron cursos optativos y seminarios relacionados con el tema, uno de ellos cuenta con estudios sobre clínica psicoanalítica. Dos de ellos tienen estudios de posgrado sobre drogodependencias, otro tiene posgrado en psicología clínica, esta formación de posgrados permitió obtener competencias para desempeñarse en el campo clínico y con la población de drogodependientes, experiencias que son considerados como valiosas y semejantes a la formación académica. Dos de ellos, ambos del modelo clínico, cuentan con más de 10 años de experiencia, tanto en el modelo de comunidad terapéutica como en el modelo clínico, y además ambos tienen especialización en farmacodependencia (FUNLAM) y específicamente uno de ellos cuenta con una Maestría en drogodependencias (CES). Este último sigue la orientación psicodinámica, mientras que el primero se orienta por la cognitivo conductual, además cuenta con cursos en el modelo Matrix. En cuanto a los dos psicólogos del modelo comunidad terapéutica, son de orientación psicodinámica, además uno de ellos está realizando una especialización en patología de estructuras (UdeA). Por último cabe destacar la influencia de la experiencia de trabajo con colegas de mayor experticia y que poseen otros saberes (medicina y psiquiatría), la cual es valorada como formativa, así por ejemplo, uno de ellos refiere que (P1MC): "desde 2011 que trabajo en la institución conocí un psiquiatra, el doctor Ulloa, ha habido mucho aprendizaje, aclara uno más cosas, también pues con el director, que es médico y doctor en psicología, pues es un personaje que no se guarda la información, él la da a conocer." En resumen, estos psicólogos poseen las competencias clínicas (títulos académicos y experiencia laboral) necesarias para desempeñarse en el tratamiento institucional de las drogodependencias en Colombia, cumpliendo así con los requerimientos exigidos según las disposiciones científicas y legales revisadas (Becoña \& Cortés, 2011; COLPSIC, 2014; MINSALUD \& UNODC, 2016).

Al respecto, en la subcategoría 3.2. Características positivas del psicoterapeuta, los pacientes confirman la importancia de la experiencia clínica del psicoterapeuta (Pa2MC): "hemos hablado de técnicas y todo eso, pero no propiamente como para aplicarla sino para explicarlas, el trabajo que se ha hecho, se ha hecho más así como desde la experiencia y no desde un determinado modelo, de una determinada técnica, yo creo que es más importante la experiencia que los modelos ya preestablecidos." Además, los pacientes describen que los psicólogos muestran (Pa2MC): "mucho profesionalismo," o también que (Pa2MCT): "es una persona muy noble, muy inteligente" o que (Pa4MC): "es muy calmado."

En ese orden de ideas, en la subcategoría 3.3. Actitud clínica, notan una diferencia según la cual es distinto (Pa3MC): "el psicólogo que hace las cosas por amor, porque le apasiona, pero hay otro psicólogo que hace las cosas por plata," haciendo referencia al interés genuino del psicólogo por la persona y su problemática, es decir, la actitud clínica del psicoterapeuta frente al paciente en la que demuestra interés real en sus problemas, síntomas e historia de vida, sin juzgar y mostrando una postura comprensiva (Brenstein \& Nietzel, 2011; Lambert \& Barley, 2001; Mayor et al., 2018). Es que según los pacientes el psicólogo (Pa3MCT): "siempre era pendiente, si lo ve a uno triste, que tiene, venga cuénteme, lo ayuda sobrellevar," de modo que ellos captan que el profesional (Pa1MC): "esta vigilante con uno, así uno no cuente las cosas él nota cuando uno está aburrido, tiene problemas, él siempre está pendiente del usuario, lo que más me gustó fue que él era muy perseverante, el perseveraba mucho de una y otra forma, la constancia de él estar siempre, de una u otra forma esto ayuda mucho."

La categoría cuatro: concepciones de las drogodependencias, muestra las diferentes miradas de los clínicos acerca de las drogodependencias, destacándose el hecho de que la visión de estos (más psicológica) difiere de las concepciones institucionales, de corte más médico, 
según las cuales, básicamente se trataría de una enfermedad neurológica, los entrevistados (excepto uno) difieren parcialmente de las concepciones institucionales de las organizaciones en las cuales laboran. Todos concuerdan en que el modelo cognitivo conductual es el más usado en las comunidades terapéuticas y/o centros de rehabilitación, corroborando lo que se ha descrito en la literatura científica (Becoña \& Cortés, 2011; Goti, 2003, 2009; Kooyman, 1996), mientras que en el modelo clínico usan más el modelo motivacional Matrix, que es menos coercitivo con los pacientes, además de que se inscribe en los modelos de prácticas basadas en la evidencia científica, en acuerdo con los estudios más recientes (Daset \& Cracco, 2013; Echeburrua et al., 2010; Martínez-Taboas, 2014; Quant \& Trujillo, 2014). Al respecto, dos de los psicoterapeutas (uno de modelo clínico y otro de comunidad terapéutica) muestran diferencias respecto de las concepciones médicas y cognitivo conductuales que guían las intervenciones institucionales, así por ejemplo, uno de ellos dice que (P1MCT): "allí si entra todo eso de lo conductual, entonces sería entenderlo más desde una base psicológica," mostrando así la necesidad de usar un enfoque psicológico distinto al conductual para poder "entender" a la persona. Así mismo, otro de los clínicos confirma que la concepción de las drogodependencias usada en su institución es la de (P1MC): "una enfermedad del cerebro y no tiene cura, es una enfermedad crónica para toda la vida, una persona que sufre para toda la vida, puede que deje la sustancia, pero se tiene que seguir cuidando," evidenciando una concepción médica, que sin embargo, reconoce a la persona que padece dicha enfermedad, con lo cual se observa una diferencia entre la concepción anatomo fisiopatológica institucional, en contraste con una visión más humana y psicológica del profesional, concepciones clásicas en los estudios científicos presentados en la introducción (Becoña \& Cortés, 2011; Goti, 2003, 2009; Laing, 2015; OMS, 2004; NIDA, 2018). Esta diferencia también se observa cuando hace la comparación entre las terapias de choque del modelo conductual y otros modelos, afirmando que: (P1MC): "hay cosas que de pronto no me gustan mucho, lo que es el tema del grito, cierto, claro que hay personas que le funcionan todos los modelos, para cada modelo hay personas que le funcionan, todos son buenos," lo cual recuerda la experiencia de Maslow al conocer las primeras comunidades terapéuticas y sus métodos de trabajo que incluían un tono de voz alto "como un acto brusco de honestidad" en las intervenciones (Kooyman, 1996).

Por otro lado, éste psicoterapeuta resalta algunas ventajas del modelo Matrix, señalando que éste le permite hacer verdaderamente psicología clínica desde un enfoque cognitivo conductual, en cuanto a la anamnesis, informa que éstas serían mucho más completas desde una postura más comprensiva en la cual (P1MC): "el clínico ya se dedica directamente a la persona, a ese ser, a hacerle una evaluación, a ver que diagnóstico puedo obtener de él, lo trabaja más, más a fondo, cierto, como individuo." Así mismo, éste clínico muestra otra distancia del enfoque conductual y una identificación más con el modelo motivacional cuando dice (P1MC): "yo por ejemplo que he estado también en el modelo conductual es muy de cambios de conductas, de normas, mientras que en el modelo Matrix, es un modelo más motivacional, donde hay que buscar el cambio del muchacho desde la motivación, porque obligado él no va a cambiar," corroborando lo expresado por Becoña y Cortés (2011) y Mayor, Noval, Cepedello, y Prieto (2018) quienes resaltan la importancia de los aspectos motivacionales para el logro de objetivos. Agrega, además, una crítica al uso riguroso de los protocolos propios del modelo clínico: (P1MC): "nuestros protocolos son muy estrictos, se estudia el paciente, cuál es su diagnóstico, que hace el paciente, que dice el paciente, pero en mi concepto yo lo he visto como más clínico que en el modelo Matrix, donde se trabaja la parte clínica, yo igual los evaluó, igualmente les hago terapia, parte del Matrix." En síntesis, éstos psicólogos corroboran que existen diversas concepciones de las drogodependencias y diversas formas de intervención clínica (Becoña \& Cortés, 2011; Pacheco et al., 2013).

También es importante resaltar otras diferencias entre el modelo de comunidad terapéutica y el clínico, donde se cuestiona el modelo clínico basado en la evidencia científica, 
al respecto otro clínico afirma que (P2MC): "nunca hacemos intervenciones basados en espiritualidad," señalando así un vacío o contradicción en la intervención, que debería ser integral, según las leyes y disposiciones internacionales, así como las colombianas. (OMS, 2004; MINSALUD \& UNODC, 2016; NIDA, 2018), y los estudios más recientes sobre eficacia terapéutica en drogodependencias (Hai et al., 2019). En este sentido, explica que su institución (P2MC): "al ser un enfoque médico tenga una vertiente mucho más técnica, porque todo lo que se hace allí debe estar bajo la evidencia científica, entonces, la palabra, nosotros nos terminamos restringiendo de esto, pero casi que no podemos hacer nada que no tenga evidencia científica ¡si!, entonces cuando uno propone cierta cosa, la respuesta es, tráigame los artículos donde se aborde y que referencien eso." Esto contrasta con otras concepciones de la clínica que privilegian la relación con la persona y dan importancia a los aspectos espirituales de ésta (Goti, 2003, 2009; Hai et al., 2019; Kooyman, 1996). En resumen no comparte totalmente la concepción de las drogodependencias del modelo clínico, de práctica basada en la evidencia científica, veamos (P2MC): "yo soy un poco crítico de entender, por ejemplo la farmacodependencia como una enfermedad, es un asunto meramente político que el estado finalmente tiene que brindar recursos para esto, tiene que decir que es una enfermedad, de lo contrario no se podía reconocer recursos, yo siento que la farmacodependencia en lo personal no es una enfermedad crónica, como mucha literatura lo ha dicho, difiero un poco de eso, siento que digamos es un trastorno que tiene cura en mi concepto."

La categoría cinco: competencias del psicólogo, evidencia las principales competencias que debe tener un psicólogo clínico en estas instituciones, puesto que allí se requiere de profesionales con un perfil en el que se integre el manejo de límites, la autoridad y la sensibilidad, la comprensión empática, entre otras capacidades, habilidades o competencias, que permiten hacer señalamientos, interpretaciones y devoluciones, evitando la generación de resistencias. Esta incluye las Subcategorías; 5.1. Empatía (sensibilidad y manejo de la autoridad); 5.2. Directividad/No directividad terapéutica; y 5.3. Raport, aceptación incondicional, profesionalismo y neutralidad. En la subcategoría 5.1. empatía (sensibilidad y manejo de la autoridad), evidencia que todos los entrevistados destacan la importancia de ésta capacidad, en acuerdo con los más destacados clínicos, como un factor indispensable para que los procesos de evaluación, diagnóstico y tratamiento se desplieguen de la manera adecuada (Brenstein \& Nietzel, 2011; Casari et al., 2017; Chacón, 2016; Corominas \& García, 2014; Durán et al., 2007; Lambert \& Barley, 2001; Mayor et al., 2018; Pacheco et al., 2013; Rogers, 2010), pues se pretende (P2MC): "generar empatía o rapport y ser sensible ante la situación del otro, buscando propender por generar la menor iatrogenia posible." La anterior frase evidencia además que estos psicólogos deben tener otra característica, sensibilidad, lo cual implica un rasgo de personalidad que favorece el rapport, ya que (P2MCT): "el proceso terapéutico depende también mucho de la personalidad del psicólogo," que se caracterice por la sensibilidad y la capacidad empática (Laing, 2015; Lambert \& Barley, 2001; Pacheco et al., 2013; Rogers, 2010). Así mismo, ellos destacan otro rasgo de personalidad; un carácter firme y por ende un comportamiento ético en la relación con los pacientes, pues dadas las problemáticas de manejo de la norma en la población drogodependiente es fundamental no asumir posiciones permisivas ni asistencialistas (lástima o pesar), manteniendo el rol de una figura de autoridad, que sin embargo, tampoco asume posiciones autoritarias, veamos, (P1MCT): "una persona que esté muy aterrizada, porque es que uno aquí entra a ser en cierta medida una parte de autoridad para ellos, entonces si uno llega a ser una persona muy permisiva, no es autoritaria es tener una base sólida, la empatía es muy importante en el proceso." En resumen, se necesita una personalidad que integre el manejo de la autoridad, la sensibilidad y la empatía al mismo tiempo, confirmando el perfil descrito en las investigaciones más recientes (Casari et al., 2017; Corominas \& Garcia, 2017; Goti, 2003, 2009; Kooyman, 1996; Mayor et al., 2018; Pacheco et al., 2013). 
Lo anterior, también se observa al analizar la subcategoría 5.2. Directividad/no Directividad Terapéutica, ya que evidencia la necesidad de que el psicoterapeuta conduzca la relación desde una posición directiva que permita el logro de objetivos, tal como lo confirma un paciente quien reporta que su psicólogo le indicaba que debía de (Pa2MCT): "hacer cosas que lo lleven bien, haga esto con su familia, diga esto, y yo realmente lo he puesto en práctica y me ha salido muy excelente, lo guía a uno muy bien," así mismo, otro paciente explica que su psicólogo le dejaba (Pa4MCT): "tareas para hacer." Sin embargo, esta directividad debe ser parcial para que los pacientes se responsabilicen de su propio proceso, así por ejemplo un paciente dice que su psicólogo (Pa2MC): "ha sido más espontáneo, que no explicarle a uno vamos a hacer esto, vamos hacer lo otro, que sale de un diálogo que va fluyendo." De igual forma, otro de ellos comenta que en su caso han trabajado (Pa4MC): "dejándome a voluntad, mi propia voluntad, no acercándoseme mucho, si no que esperando de que yo mire como son las cosas, pues por aquí sin ellos estando como un papá, como una mamá o cómo un policía."

De otro lado, en la subcategoría 5.3. Raport, aceptación incondicional, profesionalismo y neutralidad, los psicoterapeutas destacan la importancia de la constancia y la tolerancia a la frustración, debido a los típicos fenómenos de las recaídas que implican un reto permanente para los clínicos. Al respecto, uno de los psicólogos del modelo clínico explica que para tolerar estas situaciones es importante que a los profesionales (P1MC): "les guste trabajar con este tipo de población, porque los drogadictos empiezan su tratamiento y vuelven y recaen, vuelven y cogen el tratamiento, vuelven y caen, entonces uno tiene que estar constantemente dele, dele, dele, son pocos los que se mantienen muchos años en abstinencia." Ahora bien, para que el psicólogo pueda sentirse cómodo en su quehacer y poder generar motivación para el cambio en los drogadictos, es necesario que tenga dos competencias fundamentales, ampliamente reconocidas en psicología clínica; la neutralidad (Freud, 2007) y la capacidad de aceptación incondicional (Lambert \& Barley, 2001; Rogers, 2010), tal como lo muestra la siguiente frase: (P2MC): "debe tener claro su capacidad para no juzgar al paciente por sus decisiones, además manejar el sentimiento mesiánico que surge con cada caso de éxito." Por último, concuerdan en que el clínico debe tener un adecuado conocimiento sobre el fenómeno de la drogodependencia (P2MC): "debe ser consciente que la farmacodependencia se encuentra en pleno desarrollo descriptivo y epistemológico, y por lo tanto no existe una única verdad, solo aproximaciones fenomenológicas, ésta es la razón por la cual hoy en día se desconoce la génesis, su desarrollo y el pronóstico de los pacientes que realizan tratamiento para la deshabituación del consumo de sustancias psicoactivas, esto exige por parte del psicólogo una revisión constante de la literatura, con el fin de tener un acercamiento más claro al fenómeno. Exige entonces la formación permanente, no adherirse a un solo enfoque y ser cambiante de su enfoque a medida que se realizan nuevos estudios y descubrimientos." Además, señalan que todos los enfoques teóricos de la psicología serían válidos y necesarios, así como el apoyo con la farmacología y la psiquiatría (Becoña \& Cortés, 2011). Al respecto, queremos destacar que uno de los psicoterapeutas considera importante el saber práctico o empírico que pueda tener el psicólogo acerca de las drogas, veamos: (P1MC): "que conozca las drogas mucho mejor, si éste psicólogo en algún momento tuvo algún problema con drogas, entonces va a entender mucho más al paciente drogadicto." Finalmente, solo uno de los entrevistados considera importante que el clínico conozca acerca de guías y protocolos de intervención (P2MC): "Igualmente, debe contar con competencias desde el hacer, conociendo y siguiendo al pie de la letra el código de ética y las guías de intervención establecidas para tal fin, el correcto diligenciamiento de los registros," como puede verse, el clínico olvida la necesaria flexibilidad y contextualización de las guías, tal como él mismo lo señalan en otras partes de la entrevista, en acuerdo con sus propios colegas y los expertos en las PBE. (Daset \& Cracco, 2013; Martinez-Taboas, 2014, Quant \& Trujillo, 2014). 
La categoría seis, estrategias clínicas, incluye estrategias de intervención psicoterapéutica de diversos enfoques psicológicos utilizadas en estas instituciones para promover el logro de los objetivos (eliminación sintomática, entre otros), que además favorecen la adherencia al proceso, entre las cuales se destacan la entrevista motivacional, la escucha activa y las devoluciones que dan cuenta de la actitud clínica de los psicoterapeutas, quienes inicialmente logran "enganchar" a los usuarios para luego, en los momentos finales del proceso, hacer un cierre de estos que favorezcan la autonomía y la reinserción socio-laboral. Esta categoría fue la más extensa e importante y muestra que, en general, priman las estrategias cognitivo condutales enfocados a la eliminación sintomática, aun cuando, reconocen la necesidad de utilizar otras estrategias de los enfoques comprensivos (psicodinámicos y humanistas) en razón de la eficacia de éstas para favorecer la relación terapéutica y la adherencia al proceso. Esta categoría incluye las subcategorías; 6.1. Relación terapéutica; 6.2. Interpretación o devolución; 6.3. Tranquilidad; 6.4. Confianza; 6.5. Alianza terapéutica; 6.6. Desahogo o catarsis; 6.7. Comunicación contextualizada; 6.8. Motivación y Participación del paciente; 6.9 Apertura al cambio; 6.10. Transferencia.; 6.11. Evaluación y Diagnostico; 6.12. Proceso por etapas; 6.13. Psicoeducación; 6.14. Adherencia y Aprovechamiento del tratamiento; 6.15. Reconocimiento de la subjetividad del paciente y uso Dialéctica; 6.16. Logros terapéuticos; y 6.17. Reinserción sociolaboral y prevención de recaídas

La subcategoría 6.1. Relación terapéutica, aparece como un factor importante que permite el despliegue de las estrategias utilizadas por el psicólogo, así por ejemplo, en la siguiente frase se ilustra la importancia de la relación terapéutica (P1MCT): "Yo hago desde mi personalidad, adaptarme al paciente desde su individualidad y ver cómo podemos hacer que se adhiera al tratamiento y continuar con su proceso desde el área psicológica, está la empatía, la cercanía, el hecho también de poner límites claros en la relación con ellos," pues como indica un paciente (Pa1MCT): "Es una relación afectiva, de amistad," o también (Pa2MCT): "ha sido como de amigo, como de parceros."

Al respecto, en la subcategoría 6.2. Interpretación o devolución, resulta evidente la importancia de crear una relación de confianza que permita que el paciente se cuestione así mismo. En psicología clínica se recomienda mantener una actitud profesional acorde con el rol de psicoterapeuta, evitando que se involucre la subjetividad de éste, pues ello podría dificultar asumir una posición objetiva y neutral que permita hacer interpretaciones, señalamientos y devoluciones a los pacientes de forma profesional, ya que, pueden sentirse como algo displacentero (Pa4MC): "el psicólogo es como un amigo sincero, un amigo franco que le dice a uno las cosas como son, pero delicadamente." Sin embargo, estos señalamientos son parte fundamental del proceso clínico, razón por la cual debe tener claro que no es una relación de amistad, aunque el paciente al principio lo sienta así, ya que, los pacientes describen ésta relación como amena o agradable, así por ejemplo uno de ellos reporta que (Pa1MCT) "la conversación se vuelve amena, se vuelve agradable, la relación es muy asertiva, de amabilidad, de motivación y escucha, me he sentido bien, encuentro una armonía." O según otro paciente (Pa3MC) "la relación que el establece conmigo me parece muy chévere, muy activa, es una relación como bacana, chévere, es muy afectiva, claro está pues, que nada de abrazos, son saludos cordiales," de modo que, según los pacientes (Pa4MCT): "se siente como un apoyo psicológico."

En ese mismo sentido, la subcategoría 6.3. Tranquilidad, destaca elementos esenciales de la psicología clínica como (P2MC): "tener nivel alto de empatía, por lo menos de no juzgamientos," puesto que, según uno de los pacientes (Pa4MCT): "he sentido como la tranquilidad de comentarle a alguien que no es mi amigo, que no es un conocido, que no es un familiar, sino que es alguien que uno entiende que es un profesional," el cual debe adoptar una posición de aceptación incondicional, que le permite no juzgar a los pacientes, promoviendo la 
empatía al reconocer la vulnerabilidad del otro, de modo que abarca la actitud profesional, pero también la posición humana, generando confianza en el paciente.

Por ello, la subcategoría 6.4. Confianza, muestra que la comprensión empática y la aceptación incondicional promueven la confianza del paciente en el psicoterapeuta, puesto que según uno de ellos (Pa1MCT) "Yo creo que el acercamiento, individual ha sido de mucha confianza, se han abierto los espacios para poder tratar los temas," o también reportan que el psicoterapeuta (Pa3MC): "es una persona que le da cierta confianza, aparte de ser un profesional en salud, se va convirtiendo como en un compañero, lo escucha, lo entiende, se va generando compañerismo, confianza mutua." Se entiende entonces que la comprensión empática implica una confidencialidad que promueve el establecimiento de la relación terapéutica, puesto que genera confianza en el psicólogo, al respecto un paciente informa que (Pa2MCT): "le dije a él cosas que realmente nunca se las había contado a nadie," según otro paciente se siente (Pa3MCT) "como en familia, siento que puedo confiarle mis cosas sin temor a que el valla a decir," lo cual, sumado a la escucha terapéutica, afianza la relación con el profesional, ya que, según un paciente (Pa1MCT):"me siento escuchado, me siento muy tranquilo al expresar todos los sentimientos," y es que según otro paciente (Pa4MCT): "la estrategia fundamental que ha utilizado ha sido que ella me ha escuchado, cosas que uno no se las cuenta totalmente a un familiar, porque le da pena, mientras que un profesional que no lo conoce a uno se da como esa capacidad, se convierte en un confidente de uno, sin ser amistad de uno para nada," lo que se traduce en una posición de honestidad del paciente, veamos (Pa2MCT): "hay cosas que uno no quiere contar de su problemática, algo que tiene guardado."

En ese orden de ideas, la subcategoría 6.5. Alianza terapéutica, muestra la importancia de establecer un vínculo de trabajo en el que el paciente asumen una posición activa y aporta al logro de objetivos, por lo cual uno de ellos explica que (Pa2MC) "si yo no le hablo, él no tiene forma de trabajar," lo cual es indispensable para crear alianza terapéutica, corroborando los hallazgos de (Arango \& Moreno, 2009; Goti, 2003, 2009; Kooyman, 1996). En resumen, la confianza, la confidencialidad y la honestidad, todo ello favorece el establecimiento del rapport y el desahogo emocional o catarsis.

La subcategoría 6.6. desahogo o catarsis, evidencia que ésta estrategia psicoterapéutica representa un proceso importante para el logro de objetivos, puesto que según algunos pacientes (Pa2MCT): uno necesita desahogarse, uno no cuenta todo a todo el mundo, ni a su familia, solo al psicólogo," o también que según otro paciente es importante poder tener (Pa4MCT): "un desahogo de cosas que uno tiene por dentro, y que no le puede contar a nadie," razón por la cual un psicoterapeuta explica que la catarsis se favorece el (P2MC): “dejar que el paciente hable, si uno se muestra muy académico, entonces ellos se van a sentir directamente inferiores a uno, la idea es que usted tenga la capacidad de bajarse a su estado, de bajar a su mundo, intervenir bajo su lenguaje, podríamos intervenir desde ese mundo y hablar desde ese mundo y eso genera mucha más empatía y adherencia."

La subcategoría 6.7. comunicación contextualizada, muestra la importancia de utilizar adecuadamente el lenguaje y la palabra en la relación terapéutica, al respeto, los pacientes corroboran la importancia de la comunicación contextualizada, cuando dicen que el psicólogo debe (Pa2MCT): "saber hablar, saber mirarlo a uno como persona," ya que (Pa2MC): "el lenguaje que se utiliza, no es pues una cuestión de términos médicos, los nombres científicos de una cosa o la otra, sino que sí se le dice como comúnmente se le conoce a las cosas, pues hay más diálogo, más abierto y comprensible, la empatía con el psicólogo ha influido positivamente." Así mismo otro paciente resalta (Pa2MC): "la importancia de que te hable en un lenguaje coloquial, más que como profesional, como un aspecto más amigable, darle una confianza, de no tocar las cosas de un aspecto como muy científico, más cotidiano, un lenguaje no tan científico y todo eso, si no más que todo como poniéndose los zapatos de uno, más simpatía [empatía], es la apertura que él le da a uno para que pueda empezar a soltarse, abrirse 
al proceso." Lo anterior evidencia una estrategia de comunicación que permite decodificar el significado que los pacientes y psicoterapeutas dan a sus experiencias en su discurso. Así mismo, uno de los psicólogos busca: (P1MC): "hacerlos sentir grandes, es que usted sabe mucho de eso, es que usted tiene mucha experiencia, eso los hace sentir bien y eso muchas veces es lo que los enganchan con el tratamiento." Es evidente que el trabajo clínico depende directamente de la relación terapéutica, ya que (P2MCT): "el mismo vínculo que se forma es lo que se usa para trabajar, es el fundamento de todo, si la relación progresa, el proceso progresa."

La subcategoría 6.8. Motivación y participación del paciente, resalta la importancia de la posición activa de éste en la consecución de logros, en el caso de los pacientes con baja capacidad de introspección o con personalidad introvertida, los psicoterapeutas suelen utilizar estrategias motivacionales para favorecer la participación en las actividades, puesto que: (P1MC): "esa participación también hay que motivarla porque hay pacientes que no hablan."

El análisis de la categoría seis revela coincidencias entre los entrevistados (psicoterapuas y pacientes) y los aportes de los expertos en psicología clínica, pues los pacientes también confirman la importancia de la motivación como activación interna, que dirige nuestros comportamientos y actitudes, que surge de acuerdo a las necesidades individuales, de diverso orden (primarias secundarias y terciarias), y que en el tratamiento de las drogodependencias puede favorecer o entorpecer el proceso (Brenstein \& Nietzel, 2011; Casari et al., 2017; Chacón, 2016; Corominas \& García, 2014; Durán et al., 2007; Linn \& Garsken, 1993; Pacheco et al., 2013; Rogers, 2010), por ejemplo, puede afectar los niveles de adherencia de los pacientes, veamos, (Pa1MCT): "Ha sido el kit de arranque para seguir con otros procesos, ha sido una evolución de crecimiento, de fortalecimiento de convicción," existiendo distintas estrategias para incrementar la motivación, así algunos psicoterapeutas utilizan técnicas cognitivo-conductuales de reforzamiento y reflexión, por ejemplo a uno de los pacientes el psicoterapeuta le (Pa1MC): "daba una chocolatina, también me daba unos papelitos con mensajes, entonces, eso ayudaba mucho porque yo los sacaba y los leía y eran positivos."

En este orden de ideas, la subcategoría 6.9. Apertura al cambio, ilustra que la motivación también surge internamente en el paciente, debido a un deseo de cambio, pero ésta motivación puede ser favorecida u obstaculizada en razón de factores externos, entre los cuales se destacan las relaciones interpersonales que los pacientes establecen con familiares y terapeutas en el transcurso del proceso, tal como comenta un paciente quien dice que (Pa4MC): "detrás de ese alguien hay muchas personas que están haciendo algo por uno, y que quieren el bien para uno," siendo importante conocer si el motivo de consulta es propio o de un tercero, ya que, en muchos casos los propios pacientes reconocen que ingresan (Pa1MCT): "por voluntad propia y por la promesa que le hice a mi mamá."

La subcategoría 6.10. Transferencia, enseña que la relación terapéutica reproduce elementos de vínculos personales del paciente, al respecto un clínico informa que (P2MC): "uno termina siendo como un modelo, no es la persona, pero si la ideología, ellos se adhieren mucho a esa ideología, entonces ven que uno tiene una ideología muy propositiva y eso termina generando mucha adherencia, termina generando esa empatía a través de la ideología que te pone el paciente, finalmente somos como se dice el sujeto supuesto saber," lo cual hace referencia al conocido concepto del psicoanálisis Lacan (2009), además agrega que (P2MC): "sin uno quererlo termina siendo el reflejo del papá, uno termina siendo el reflejo de la mamá, ahora termina siendo el reflejo de la novia o del novio y uno tiene que aprender," lo que recuerda el concepto psicoanalítico de transferencia (Freud, 2007). Es que según los propios pacientes (Pa3MC): "haga de cuenta que esto es como una relación como de novios, sin picos y sin abrazos cierto, pero si usted le dice mentiras a su novia, usted va pa' bajo, si usted le habla con la verdad va para arriba.” Por último, resaltan la importancia de la relación terapéutica, al 
señalar que el psicoterapeuta debe tener (P2MCT): "calma, tranquilidad, porque están muy angustiados, la escucha, me parece que eso es lo más importante," lo que confirma otro paciente cuando dice que (Pa4MCT): "es una relación que a mí me genera tranquilidad, estabilidad y seguridad." Como puede verse, la relación terapéutica permite que los pacientes experimenten estados de tranquilidad en algunos momentos del proceso, puesto que en otros, puede producir emociones displacenteras como la angustia, la ira y la tristeza, que se generan producto de las interpretaciones o devoluciones.

En cuanto a las estrategias para producir modificaciones conductuales y psíquicas, la subcategoría 6.11. Evaluación y diagnóstico, muestra la importancia otorgada a las actividades de staff, puesto que, según una psicoterapeuta, luego de la evaluación integral desde cada área, (P1MCT): "desde el staff se pone como el caso y desde allá se brindan estrategias." Además, el staff permite aclarar las hipótesis diagnósticas y por ende diseñar planes de intervención adecuados para el caso por caso, ya que (P1MC): "hay pacientes mal diagnosticados." Por otro lado, otro clínico subraya que las estrategias de cambio están basadas en (P1MCT): "lo conductual y lo cognitivo, se utiliza mucho lo que es el diálogo, lo práctico, la toma de decisiones, los estilos de vida saludable, habilidades para la vida, pero mirando al paciente, los controles de impulsos, está esto del discurso, y la confrontación," coincidiendo con lo planteado por Becoña y Cortés (2011), quienes reportan la primacía de estas estrategias cognitivo conductuales.

La subcategoría 6.12. Procesos por etapas, enseña que el logro de objetivos se produce de forma ordenada, según las fases o etapas preestablecidas, al respecto informan los clínicos que (P1MC): "hay un protocolo, ese protocolo trae unas sesiones y prácticamente son las estrategias, las estrategias que uno utilice para trabajar las ideas irracionales, manejo de pensamientos automáticos, los distractores," por lo cual los logros no se producen inmediatamente, ya que, como lo plantea uno de los pacientes (Pa1MC): "hay que hacerlo paso por paso, si como decir solo el día de hoy," refiriéndose al modelo de los doce pasos de Alcohólicos Anónimos, al tiempo que muestra la complejidad del proceso, (Pa1MC): "las cosas no se dan de una vez, uno no puede ser inmediatista, hay que trabajar y trabajar hasta que las cosas se den, el progreso de muchas etapas." Sin embargo, los psicólogos también usan otras estrategias propias de otras corrientes psicológicas, ya que, según ellos (P1MC): "a veces se deja permear de otras corrientes, la relajación, la actividad física, estrategias como ayudarles a ellos con el tema de la alimentación" (Becoña \& Cortés, 2011), lo cual confirman los pacientes, quienes informan que han utilizado (Pa2MC): "una relajación o meditación, la regresión hasta cierta parte de la infancia," o también el (Pa4MC): "manejar una ansiedad con una pelotica o con un cauchito."

Uno de los clínicos también informa la importancia de (P2MC): "utilizar elementos muy cercanos como a las analogías." Además, destacamos un aspecto esencial que facilita el logro de los objetivos terapéuticos, a saber; la seguridad que trasmite el terapeuta y promueve la transferencia (Freud, 2007), pues el vínculo se afianzaría, pues según uno de los psicoterapeutas: (P2MC): "cuando usted demuestra que sabe, cuando usted demuestra qué tiene conocimiento y demuestra seguridad de sus intervenciones, pero si tú no demuestras seguridad, créeme que el usuario termina diciendo quiero cambiar de psicólogo."

En la subcategoría 6.13. Psicoeducación, se resaltan las estrategias pedagógicas o psicoeducativas que complementan el abordaje puramente clínico, veamos algunos testimonios, así por ejemplo un paciente refiere que este tipo de intervención le (Pa2MCT): "ha dado como estrategias de modificar mi entorno de vida," o también que a través de estas actividades (Pa4MCT): "uno aprende, o sea que con estos manuales aprende uno como abrir la mente," ya que a través de (Pa3MCT) "libros, también las charlas, aportan al desarrollo y crecimiento humano," por lo que ayudan al logro de los objetivos terapéuticos. 
La subcategoría 6.14. Adherencia y Aprovechamiento del tratamiento, describe las estrategias que favorecen la adherencia terapéutica, entre las cuales se destacan la escucha del caso por caso, el uso de un lenguaje no técnico y más cercano a los usuarios, la creatividad, entre otros factores que crean un clima de rapport, pero el factor más valorado es (P1MC): "el saberlos escuchar y la entrevista motivacional," en acuerdo con lo planteado por Becoña \& Cortés (2011). Según los psicoterapeutas otra de las estrategias que muestran eficacia sería (P2MC): "ese feedback de devolverle parte de sus discursos, de sus palabras, de devolverle lo que él me dijo, eso exige mucha más atención por parte del psicoterapeuta, pero esas cosas son las que si tú le pones cuidado a estas pequeñas cosas que él dice y tú se las devuelves después al final de la sesión, o en la sesión siguiente, tienes una adherencia muy fuerte que el paciente te va a decir, es que él si me escucha." Así mismo, un paciente comenta que su psicoterapeuta toca (Pa2MCT): "los puntos que yo si siento que tengo que transformar, uno se pone a analizar y es como él lo dice."

La subcategoría 6.15. Reconocimiento de la subjetividad del paciente y uso de la dialéctica, muestra la importancia que los clínicos otorgan a las diferencias individuales, lo que implica el reconocimiento de la subjetividad del paciente (Beck et al., 2012; Bruner, 2009; Freud, 2007; Canguilhem, 2014; De Castro \& García, 2017; Gadamer, 2017; Lacan, 2009; Laing, 2015; Perls, 2016; Piaget, 1983; Rogers, 2010; Winnicott, 2013; Yalom, 2010) puesto que según los clínicos (P1MCT): "es muy importante la historicidad de cada uno, y ahí es donde dan y develan la subjetividad de cada uno," ya que (P1MC): "cada paciente es un mundo diferente," por lo cual se debe tener presente que:(P2MC): "no se puede generalizar ninguna problemática, porque cada realidad es totalmente distinta y si bien los síntomas son similares, hay cosas que lo hacen único," razón por la cual se emplea la dialéctica y en general el método del debate socrático que permite al paciente y al psicoterapeuta reconocer la subjetividad y lo singular de la historia de vida, tal y como comenta un paciente cuando dice que: (Pa4MCT): "Yo pienso que lo que más ha influido en esta relación ha sido el conocimiento, cuando se empieza el proceso, el psicólogo no sabe nada de ti, cuando se empieza a exponer mi caso." De ahí la importancia de realizar adecuadamente la anamnesis, pues según este paciente (Pa4MCT): "primero empezamos en cómo ha sido mi vida desde pequeño, le he compartido mucho mi vida desde niño, como empezó mi niñez, las cosas que se le han marcado a uno."

En cuanto a los logros obtenidos en estos procesos, la subcategoría 6.16. Logros terapéuticos, los pacientes destacan una mayor capacidad de tolerancia, confianza en sí mismo y por parte de los demás, al respecto uno de ellos manifiesta haber adquirido, (Pa3MCT): "mucha confianza en uno mismo, a través de él [psicoterapeuta], en las tareas y en los trabajos que me ponen tengo más confianza, tengo más entusiasmo de hacer las cosas. Tengo más responsabilidad, ya ahora respeto más, se asumir, o sea las obligaciones que me dan, si hago algo malo, sé asumir las responsabilidades, con la cabeza en alto," de modo que también se (Pa3MCT) "recupera la confianza que había perdido con mi familia, ya ellos creen más en mí, lo laboral, lo personal y lo social también," según otro paciente sus logros apuntan al avance en (Pa2MC): "la falta de carácter, la toma de decisiones, también la tolerancia a la frustración, la parte del ego se ha trabajado." Otros logros se refieren al sentimiento de gratitud, veamos en palabras de otro paciente que comenta (Pa1MC): "yo creo pues que es mucha la ayuda porque yo salgo sin mi costal, yo salgo sin ese bulto que traje." Así mismo, éste también reporta un mayor asertividad (Pa1MC) "le enseña a uno a ser asertivo, en ese papel de decir no, uno como drogadicto." Para finalizar destacan los cambios en la autopercepción y la adquisición de habilidades sociales (Pa3MCT): "he sabido expresarme más, darme a conocer como persona, socializar delante de las demás personas, yo era muy tímido, ahora ya me puedo expresar sin miedo, ya tengo más confianza en mí," de modo que ellos pueden aprovechar los logros obtenidos (Pa3MCT): "todo lo que él me ha enseñado lo he puesto en práctica aquí y tanto afuera que tuve la reinserción, y todo salió bien.” 
La subcategoría 6.17. Reinserción socio-laboral y prevención de recaídas, evidencia que en los momentos finales del proceso institucional recomiendan hacer un adecuado cierre una vez se haya creado autonomía para iniciar el proceso de reinserción socio-laboral, de modo que, según los clínicos, la relación terapéutica (P1MC): "eso es algo que también hay que ir cortando con el tiempo, porque hay momentos que ya el psicólogo ya no va a estar para ese paciente y ¿qué va hacer cuando ya no esté el psicólogo? hay que enseñarle también a que se desapegue." Además, frente al cambio, consideran que (P2MCT); "ellos son los que realizan el trabajo acá, y propician el trabajo de ellos," aspecto que es reconocido por los propios pacientes al final del tratamiento (Becoña \& Cortés, 2011). Además, en la parte final del tratamiento se trabaja la prevención de recaídas, es decir, la evitación del consumo de drogas y mantenimiento de la abstinencia, ya que según unos de los pacientes (Pa3MC): "usted va a salir y va a estar el riesgo inminente ahí." En resumen, la categoría 6 confirma los hallazgos de Linn y Garsken (1993) puesto que evidencian que la eficacia terapéutica obedece a múltiples factores que son comunes a las psicoterapias de todo tipo, tales como la importancia de la relación terapéutica, el apoyo, la confianza y motivación que genera el psicoterapeuta, la posición activa del paciente, la apertura al cambio, entre otros.

La categoría siete: uso de los manuales, protocolos y guías clínicas basadas en la evidencia científica (PBE), muestra como estos son usados institucionalmente de manera flexible, en acuerdo con las sugerencias de los expertos internacionales en este campo clínico, quienes además recomiendan hacer una lectura del contexto social y cultural, cuestionando la aplicación rígida y ortodoxa de este. Esta categoría contiene los puntos de vista de los clínicos acerca de estos estándares, al igual que la incidencia de estos en el trabajo institucional, ya que en cada organización se crean, adoptan y adaptan muchos de estos documentos de trabajo que surgen en otros países. Es necesario señalar que algunos de los psicólogos (modelo de comunidad terapéutica) tienen poco conocimiento de los modelos clínicos denominados PBE, razón por la cual asemejan los manuales institucionales con los protocolos y guías basadas en la evidencia científica.

Ahora bien, los clínicos que están familiarizados con las PBE (Institución de Modelo Clínico) reconocen que es necesario capacitación para manejar estos protocolos y poder usarlos en nuestro contexto de forma adecuada, veamos (P1MC): "me tocó adoptar de varios países como 6 manuales y adaptarlos a la institución mediante un protocolo," como lo exponen \& Martínez-Taboas (2014) y Cortés, Fernández, García, Martínez, y Sierra (2018) quienes resaltan la necesidad de seleccionar y adaptar estos protocolos a la particularidad del contexto y sujeto. Así mismo, los clínicos reportan que el uso de estos son necesarios en el trabajo institucional, puesto que (P1MC): "Los manuales se están utilizando diario, es que uno tiene que trabajar es con esos manuales, se nos permite salirnos del protocolo, pero debe dejar uno la anotación, son muy estrictos con esos protocolos." Se entiende entonces que estos manuales no son usados por elección individual de los clínicos, sino por directrices institucionales, lo que implica hacer seguimiento al cumplimiento de estos protocolos, lo que puede llegar a restar autonomía al profesional, confirmando los hallazgos más recientes que muestran la necesidad de usar estos protocolos sin perder el propio criterio clínico (Daset \& Cracco, 2013; MartinezTaboas, 2014, Quant \& Trujillo, 2014).

Al respecto, uno de los clínicos informa (P1MC): "tenemos una compañera que nos hace auditoria con todo eso." Así mismo, otro clínico reporta (P2MC): "hay una persona que es un auditora externa que se encarga de leer las citas clínicas para ver si la sesión que se dio si concuerda con lo que está en el protocolo," lo que ocasiona (P2MC): "un poco de incomodidad, después uno se acostumbra, pero al comienzo si genera mucho malestar." Es por ello que los clínicos usan los protocolos con flexibilidad, veamos (P2MC): "en ocasiones yo me salgo de las guías y trabajo en la necesidad o el deseo del paciente, escuchas que otros psicólogos también lo han hecho, porque ceñirse $100 \%$ a las guías, siento que se pierde un poco 
la empatía y la escucha, entonces uno tiene que tener ojo clínico, pero que se pueda seguir en un $100 \%$, yo creo que en algún momento el psicólogo, psiquiatra o la persona que estén siguiendo nuestras guías debe salirse de ahí, porque la realidad de cada paciente es diferente y los pedidos en cada sesión son diferentes."

Lo anterior se explica, además, por el hecho de que dentro de los protocolos (P1MC): "quedan un montón de cosas, que el paciente también tiene que trabajar y que esas cositas por mínimas que sean llevan a una recaída." Por ello, uno de los clínicos dice que (P2MC): "soy partidario que hayan guías, pero que también haya la flexibilidad que dentro de esos protocolos usted se puede desviar." De ese modo concluye que (P2MC): "yo creo que la adherencia de los usuarios es menor cuando se apega uno a las guías porque el paciente se va a sentir no escuchado, se va a sentir que es lo que el otro me imponga y lo que el otro me diga." Sin embargo, considera que el uso de estas guías no representaría un problema para la relación terapéutica con los pacientes, puesto que al ser flexibles (P2MC): "ellos nunca van a percibir que eso hace parte de una estructura, de una guía que esta preestablecida." No obstante, un paciente reporta que (Pa3MC): "yo me llegue a sentir como un poco atacado, es la primera vez que yo estoy en un lugar de éstos, y cuando yo llego y veo que él me empieza a hacer una esa serie de preguntas, yo me sentía incómodo y me sentía atosigado, al principio me empecé a sentir así, pero a lo último ya me empecé a sentir un poco más relajado, al saber que era un bien para mí," confirmando así la importancia de no hacer un uso rígido de estas guías, manuales y protocolos, para favorecer la adaptación de los pacientes.

Para finalizar los clínicos concluyen que (P2MC): "el hecho de seguir una guía no quiere decir que vaya hacer exitoso, no es una garantía que el proceso vaya hacer exitoso, yo no conozco una institución que te garantice el hecho de cumplir las guías al pie de la letra, es una manera como de controlar variables que estadísticamente han demostrado que pueden generar mayor probabilidades de éxito y eso es lo que hacen las guías, digamos que estadísticamente hay mayor probabilidad de tener logro." En resumen, estos clínicos concuerdan con los expertos en cuanto a la necesidad de usar estos estándares con flexibilidad y haciendo lectura del contexto (Daset \& Cracco, 2013; Echeburua et al., 2010; Ediomo-Ubong \& Gboyega, 2019; Martínez-Taboas, 2014; Ministerio de Salud \& Oficina de las Naciones Unidas Contra la Droga y el Delito, 2016; OMS, 2004; Quant \& Trujillo, 2014; Zhang et al., 2017). Respecto a la eficacia de estas estrategias un paciente comenta que (Pa2MC): "Esas técnicas establecidas si dieron un resultado positivo," lo que evidencia las ventajas de estos manuales guías y protocolos.

En síntesis los clínicos corroboran en gran medida el seguimiento de las directrices teóricas y metodológicas aportadas por los expertos en psicología clínica frente a sus componentes esenciales y el tratamiento de las drogodependencias a nivel internacional, puesto que como se mostró, la mayoría si usan estos estándares teniendo en cuenta la importancia de flexibilizar y contextualizar estos referentes, en acuerdo con los estudios más recientes que confirman la importancia de la subjetividad y los aspectos socioculturales respecto de la eficacia de los tratamientos estandarizados (Allen \& Kaden, 1995; Echeburúa et al., 2010; Ediomo-Ubong \& Gboyega, 2019; Iudici et al., 2015; Zhang et al., 2017).

En contraste con lo presentado, hay un incremento de los clínicos que trabajan en el contexto de las drogodependencias a realizar transferencias tecnológicas; a usar manuales, protocolos y guías basados en evidencian científica, muchas veces sin en el adecuado entrenamiento, seguimiento y evaluación (Martínez \& Medina-Mora, 2013), evidenciando que todavía no es claro para muchos profesionales la forma en que deben usar estos estándares, lo que puede incidir sobre los elementos esenciales de la psicología clínica (Casari et al., 2017).

Luego de analizar las siete categorías que emergieron en el proceso investigativo, se halló que los usuarios de ambas instituciones consideran que la psicología clínica es de vital importancia en su proceso de recuperación, además, los pacientes de los dos modelos valoran 
la relación terapéutica propuesta por el psicólogo, manifestando sentirsen escuchados y entendidos, al punto de no percatarse cuando los profesionales siguen protocolos, guías y manuales basados en la evidencia científica. Por otro lado, consideran que ellos mismos son activos y participativos en su proceso de recuperación. Solo en algunos casos manifestaron inconformidad respecto a la manera en que algunos profesionales de la psicología habrían conducido las entrevistas de evaluación, en el sentido de no articular adecuadamente la empatía, la neutralidad y objetividad del profesional, por lo que percibieron la entrevista psicológica como un interrogatorio. En este sentido, los resultados de esta investigación evidencian la necesidad de lograr un equilibrio para no caer en la polarización, entre solo tener en cuenta los elementos esenciales de la psicología clínica en el tratamiento de las drogodependencias, como lo son: la subjetividad, la relación terapéutica, la empatía, el rapport, flexibilidad, la inteligencia emocional, entre otros, y la aplicación rígida de las nuevas propuestas terapéuticas con manuales, guía y protocolos basados en evidencia científica, surgidas a través de la investigación, sino que, por el contrario, se invita a mantener lo esencial de la psicología clínica articulándola a las nuevas tecnologías con actitud de apertura.

\section{Conclusiones}

Las concepciones sobre la psicología clínica que tienen los psicólogos que laboran en estas instituciones es similar, pues el trabajo clínico lo conciben como una relación terapéutica, caracterizada por la empatía, el respeto por el otro y su subjetividad, entre otros factores. Los resultados muestran la importancia de los aportes psicológicos en el trabajo interdisciplinario, en el cual el psicólogo debe asumir una posición activa y respetuosa frente a los demás profesionales, ya que el logro de objetivos es producto de la sinergia de las estrategias implementadas desde distintos saberes, pues como se dijo al inicio la drogodependencia es un fenómeno complejo y multifactorial que requiere de un equipo interdisciplinario. Así mismo, es necesario que los psicólogos promuevan la introspección, reflexión, insight, catarsis, entre otras, a través de una posición activa en la conducción del proceso que favorezca la apertura al cambio. Respecto al perfil de los psicólogos clínicos que labora en estas instituciones, estos tienen el siguiente perfil: (1) Formación académica en pregrado en psicología, (2) Cursos optativos o electivos sobre clínica o drogodependencias, (3) Estudios de posgrados (especialización o maestría) sobre clínica y/o drogodependencia, (4) Experiencia clínica y (5) Dominio teórico. En general estos psicólogos poseen las competencias mínimas del perfil del psicólogo clínico según las disposiciones legales en Colombia. Además, estos psicoterapeutas valoran el conocimiento que se deriva del trabajo con colegas de mayor experiencia. Por otro lado, los pacientes destacan algunas características positivas del terapeuta, tales como el profesionalismo, la nobleza, la tranquilidad y la inteligencia, resaltando la importancia de la confianza del clínico en sí mismo y sus experiencias previas. En cuanto a la actitud clínica, todos (pacientes y psicoterapeutas) concuerdan en la importancia de demostrar interés por el paciente y sus problemáticas, por lo cual, el monitoreo y acompañamiento de cada caso favorece el afianzamiento de la relación terapéutica.

En cuanto a las percepciones de los clínicos acerca de las drogodependencias, se destaca el hecho de que la visión de estos (más psicológica) difiere de las concepciones institucionales, de corte más médico, según las cuales, básicamente se trataría de una enfermedad neurológica. Además, evidencian un marcado predominio del modelo cognitivo conductual sobre este fenómeno, así como del modelo Matrix y en general las prácticas basadas en la evidencia científica, debido a las ventajas que ofrecen, pues por ejemplo, tienen en cuenta la parte motivacional y humana, la eficacia terapéutica, la posibilidad de replicar una estrategia estandarizada y protocolizada, entre otros. Sin embargo, los clínicos reportan acerca de la necesidad e importancia de utilizar enfoques más compresivos, de corte humanista y 
psicodinámico, por lo cual hacen una crítica a los modelos biologicista y conductual y se identifican más con el modelo psicosocial. En síntesis se observan diferencias entre los modelos de comunidad terapéutica y los clínicos, así como entre las diferentes concepciones psicológicas (cognitiva, psicodinámica y humanista) sobre las drogodependencias, que coexisten entre los profesionales y directivos de estas instituciones, siendo notable la crítica que hacen los psicólogos acerca de la falta de espiritualidad, lo que evidencia que en realidad estos procesos no siempre son integrales, pues a menudo no se incluyen o no se presta mucha importancia a la dimensión espiritual, que exigen las disposiciones legales de nuestro país.

Respecto a las principales competencias que debe tener un psicólogo clínico en éstas instituciones, allí se requiere de profesionales con un perfil en el que se integre la empatía, la sensibilidad y el manejo de la autoridad, para que el proceso clínico se desarrolle adecuadamente, requiriendo de un ambiente de rapport que facilite las actividades de evaluación, diagnóstico y tratamiento para el paciente, de modo que el psicólogo a través de su personalidad y capacidad empática genere confianza en los pacientes. Sumado a lo anterior el psicólogo debe tener la capacidad de ser directivo y promover el logro de objetivos terapéuticos, pero al tiempo debe evitar de responsabilizar al paciente y debe promover una posición activa de éste, de modo que la directividad es relativa. Por otra parte, el psicólogo debe mostrar una aceptación incondicional hacia los pacientes, es decir, una actitud de profesionalismo y neutralidad, evitando hacer juicios morales, estigmatizar o segregar. Así mismo el profesional en psicología debe tener constancia y tolerancia a la frustración debido al fenómeno típico de recaídas en el consumo. Además, estos profesionales deben poseer motivación y gusto por el trabajo con esta población y las problemáticas que los aquejan, así como un conocimiento amplio sobre el tema, por lo cual estos sugieren realizar una actualización teórica y técnica permanente, que le permita conocer los últimos desarrollos, evitando adherirse a un solo enfoque, ya que reconocen los aportes de todas las corrientes en la comprensión e intervención del fenómeno. Finalmente, algunos reconocen la importancia de tener un saber práctico o empírico sobre las drogas.

Acerca de las estrategias clínicas, en general priman las estrategias las cognitivos condutales las cuales están enfocadas a la eliminación sintomática, aun cuando reconocen la necesidad de utilizar otras estrategias de los enfoques comprensivos (psicodinámicos y humanistas) en razón de la eficacia de éstas para favorecer el fortalecimiento de la relación terapéutica y la adherencia al proceso. Además, se muestra la importancia de la entrevista motivacional, el "enganchar" los usuarios, la escucha activa, la devolución, el cierre de los procesos, entre otras estrategias que promueven la autonomía y la reinserción socio laboral de los pacientes.

En cuanto a la relación terapéutica, se destacan elementos como la capacidad empática del psicólogo y la capacidad de establecer límites claros en la relación, pues los pacientes suelen percibir esta como una relación afectiva, de amistad, siendo importante que el psicoterapeuta no confunda empatía con permisividad, dada las características de los pacientes entre las que destacan el intento de manipulación. Esto permite a los psicoterapeutas realizar interpretaciones y/o devoluciones que aunque puedan llegar a sentirse como displacenteras o dolorosas, pues señalan aspectos sensibles de reconocer, la confianza generada en la relación terapéutica permite que el paciente reconozca esas "verdades" ya que el psicoterapeuta utiliza un lenguaje contextualizado y una actitud profesional que le permiten asumir una posición objetiva y neutral, pues en el diálogo muestra tacto y prudencia al realizar estos señalamientos, de modo que los propios pacientes los describen como un amigo franco que dice las cosas delicadamente en medio de una relación amena y agradable. Esto último permite entender por qué los pacientes valoran el apoyo psicológico que surge de la relación terapéutica mediada por la empatía, pues genera tranquilidad, al no sentir juicios morales de parte del profesional, pues su actitud humana y la aceptación incondicional hacia el otro favorecen la expresión de 
pensamientos y sentimientos y por ende la comunicación con el psicoterapeuta, aportando así al logro de los objetivos terapéuticos. Es por ello que la confianza y la escucha terapéutica, sumada a la confidencialidad de la relación, crea condiciones apropiadas para que el paciente asuma una posición activa, pues estos se sienten escuchados, de modo que, a diferencia de las relaciones familiares, en esta relación pueden ser honestos, ya que no esperan juicios o rechazos y por ende se afianza la relación terapéutica. Esta alianza terapéutica requiere de la posición activa del paciente, quien deberá aporta el "material" (información) acerca de la historia de vida singular de forma honesta, lo cual permitirá que el psicoterapeuta y el paciente identifiquen aquellos elementos de la historia que serán objeto de los señalamientos o devoluciones.

En síntesis la confianza, la confidencialidad, el rapport, la honestidad del paciente favorece el desahogo emocional o catarsis, que aparece como una estrategia importante en estos procesos y que requiere de una comunicación contextualizada en la que el profesional haga uso de un lenguaje no técnico (médico-psiquiátrico-psicológico) en la relación terapéutica, para que el paciente pueda decodificar el significado del discurso, siendo importante evitar el cientificismo y más bien usar un lenguaje coloquial, además del uso de metáforas, para ayudar a facilitar la comprensión en ambos, lo que exige ponerse en el lugar del otro y comprender desde su marco referencial por ello los pacientes afirman que el psicólogo deber saber hablar y los psicoterapeutas coinciden en que hay que darle protagonismo al paciente y a su discurso.

Lo anterior incide sobre la motivación del paciente para que éste se comprometa con el proceso y participe activamente de éste, dicha motivación interna además puede ser estimulada mediante motivadores externos que también favorecen la adherencia al proceso y el logro de objetivos, tales como los conocidos reforzadores positivos y negativos de las técnicas cognitivo-conductuales, algunos pacientes mencionan desde el uso de chocolatinas hasta mensajes escritos con frases motivadoras. Esta motivación es importante, pues representa el "kit" de arranque para los procesos posteriores, los cuales requieren una apertura al cambio y una motivación interna del paciente que debe ser promovida (evitar obstaculizar) en las relaciones interpersonales con los familiares para que apoyen el proceso, pues como se sabe, en muchos casos el deseo de cambio es una motivación externa, por ejemplo, la típica promesa de a la madre, por lo cual hay que promover la participación del sistema familiar para que apoyen continuamente y promuevan esta motivación al cambio. Esta motivación además debe ser promovida por el propio psicólogo de forma constante pues en la relación terapéutica se crea vínculos afectivos que pueden influir positiva o negativamente en el compromiso y adherencia del paciente. Al respecto se describen vínculos personales que recuerdan las relaciones familiares del pasado, es decir, las relaciones objétales y la transferencia, conceptos psicoanalíticos que describen el vínculo terapéutico como algo no solo profesional, objetivo, sino como vínculo afectivo y humano donde el psicoterapeuta contiene la angustia del paciente y mediante la capacidad empática realiza interpretaciones o devoluciones sin hacer juicios morales, de modo que logra vencer las resistencias de los pacientes para que reconozcan su responsabilidad en el proceso de cambio. Por lo anterior psicoterapeutas y pacientes reconocen que los psicólogos deben mostrar seguridad y conocimiento, es decir, mostrarse como un sujeto supuesto saber, según el concepto Lacaniano. Así mismo, recordamos que el psicólogo debe manejar éticamente esta relación, debido a las emociones y sentimientos de amor y amistad que surgen en el marco de este vínculo.

Otras estrategias que favorecen la modificación psicológica y conductual hacen referencia a la importancia de un adecuado proceso de evaluación y diagnóstico, por lo cual se destaca los aportes del staff clínico, ya que permite aclara hipótesis diagnósticas y planear los planes de tratamiento e intervención de forma integral. Es notable la primacía del uso de estrategias cognitivo-conductuales para promover el rápido logro de objetivos, aunque, se reconocen que estos logros se producen por etapas, las cuales responden a un orden 
preestablecido según los protocolos institucionales que determinan las actividades a realizar y las técnicas adecuadas para promover dichos logros en cada sesión, de forma similar al conocido modelo de los doce pasos. Esto es importante pues evidencia la complejidad de estos procesos en una época marcada por el inmediatismo. Sin embargo, en estos procesos se usan multiplicidad de técnicas, estrategias o herramientas de otras corrientes psicológicas que complementan el enfoque cognitivo conductual, incluyendo además otras estrategias como la relajación, la meditación, planes de alimentación, entre otras. Por otro lado, todos destacan los aportes de la psicoeducación como un complemento al abordaje puramente clínico, pues, incentiva el aprendizaje, la reflexión y el crecimiento humano de los pacientes.

En lo referido a la adherencia y aprovechamiento del tratamiento los psicoterapeutas y los pacientes reconocen la importancia de la escucha, la devolución con un lenguaje no técnico, la entrevista motivacional, pero sobre todo destacan, la atención al discurso del paciente que permite hacer devoluciones textuales y contextuales, pues con ello se aumenta la sensación de ser escuchados. Además, reconocen la creatividad y el uso de analogías, como estrategias para reconocer la subjetividad, la singularidad, las diferencias individuales y la historicidad de cada paciente, por lo cual sugieren no generalizar, ya que se trata de distintas realidades, lo que evidencia la importancia de realizar una anamnesis de forma adecuada y completa en la que el paciente sea honesto y comunique su historia de vida con la mayor objetividad posible.

En general se reconocen como logros terapéuticos, más allá de la reducción o abstinencia en el consumo, haber adquirido una mayor capacidad de tolerancia a la frustración y de asumir responsabilidades, recuperar la confianza en sí mismos y en los demás, un cambio en la autopercepción, mayor capacidad para ordenar el proyecto de vida y tomar decisiones, así como una mayor capacidad para resolver problemas, ser asertivo y desarrollar nuevas habilidades sociales, lo cual favorece las posibilidades de reinserción socio laboral y la prevención de recaídas en el consumo. Como consecuencia de estos logros obtenidos se observa un sentimiento de gratitud en los pacientes que evidencia los resultados positivos del proceso.

En cuanto al uso de los manuales, protocolos y guías clínicas basadas en la evidencia científica (PBE), se encontró que estos son usados institucionalmente de manera flexible, en acuerdo con las sugerencias de los expertos internacionales en este campo clínico, quienes además recomiendan hacer una lectura del contexto social y cultural, cuestionando la aplicación rígida y ortodoxa de estos. Esto implica la adaptación a Colombia de manuales de otros países, o también la adaptación de los manuales de otras instituciones colombianas. Aunque todos reconocen la importancia de estos manuales, también reconocen el poco conocimiento que tienen de los mismos, ya que algunos confunden estos manuales, guías y protocolos basados en evidencia científica con los formatos institucionales, por lo cual, los propios psicoterapeutas, reconocen la necesidad de tener capacitación sobre el tema. Solo en algunos profesionales se encontraron resistencias al uso de estas guías las cuales aparecieron en los primeros momentos y que posteriormente desaparecieron al familiarizarse con estos procedimientos, por lo que progresivamente se adataron a estos, informando que si el psicólogo hace un uso contextualizado y flexible los pacientes no percibirían que hay una guía preestablecida. Sin embargo, los psicoterapeutas reconocen que un uso inadecuado (rígido) de estas guías resta autonomía al profesional, máxime cuando son objeto de auditoría constante, de modo que al no seguir paso a paso las guías pueden ser sancionados laboralmente el profesional y legalmente la institución, lo que genera presión en los clínicos. Más allá de esta presión, estos profesionales recomiendan seguir las guías, pero "saliéndose" de lo prestablecido para atender las necesidades individuales de cada paciente en las sesiones para que este se siga sintiendo escuchado y no se afecte la relación terapéutica y la adherencia al tratamiento, sin alterar significativamente la guía clínica. Por todo lo anterior concluyen que el uso a "raja tabla" de estas guías no garantiza la eficacia terapéutica, por lo cual los clínicos deben otorgar 
importancia a todos los aspectos anteriormente señalados y que constituyen la esencia de la clínica.

Para finalizar, los resultados corroboran las principales concepciones aportadas por los más destacados psicólogos, psiquiatras y psicoanalistas acerca del trabajo clínico, desde el siglo XIX hasta la actualidad, lo que permite identificar algunos puntos de vista en común, a pesar de las diferencias en las formas de entender (teorías y conceptos) el sufrimiento humano y las maneras de intervenir científicamente (técnicas). Entre los factores más destacados está la empatía, que sería una competencia esencial del psicólogo clínico, pues este rasgo de su personalidad favorece el establecimiento del vínculo o relación terapéutica, que en última instancia sería el factor esencial que promueve el cambio psicológico, el logro de los objetivos propuestos en un proceso clínico, luego de que se han realizado las actividades de evaluación y diagnóstico psicológico, las cuales resultan eficaces en la medida en que se halla creado una relación entre el paciente y psicoterapeuta caracterizada por el rapport, por la calidez, por la comprensión empática, la aceptación incondicional, la neutralidad, la abstinencia, el respeto por el otro y su subjetividad, pues ello crea una confianza básica para que el paciente pueda brindar al clínico la información que requiere acerca de su motivo de consulta (trastornos mentales y/o problemáticas psicosociales) y su historia de vida (anamnesis), ya que al demostrar una actitud clínica auténtica y original, no impostada, es decir, al mostrar interés por el otro y su sufrimiento, estas herramientas cobran gran efectividad.

Las prácticas basadas en la evidencia científica han aportado significativamente al desarrollo de las ciencias, entre ellas la psicología, pues han permitido generar cuestionamientos sobre las formas de comprensión e intervención de las afecciones mentales, de modo que muchos mitos científicos o dogmas han sido puestos en tela de juicio, permitiendo que los psicólogos de las diversas orientaciones teóricas revisen sus técnicas y teorías, a la luz de los resultados de investigaciones que intentan medir la efectividad y eficacia de estos procedimientos a través de metodologías rigurosas. Sin embargo, los expertos en estos modernos modelos clínicos que guían las acciones de los psicoterapeutas a nivel mundial, respaldados en las disposiciones legales de muchos países, incluido Colombia, cuestionan el uso inadecuado de los manuales, protocolos y guías clínicas creados a partir de la evidencia científica, pues, según lo encontrado en la revisión documental, muchos psicólogos clínicos no siguen las recomendaciones de adaptar estos modelos generales a las particularidades de la cultura, de la comunidad, del grupo, de las familias y las personas, lo que conlleva a una aplicación "ciega" de los aportes científicos, los cuales deben ser contextualizados, según los expertos. Específicamente en Colombia el ministerio de salud exige que la intervención con drogodependientes reconozca la cultura y particularidades de los sujetos, lo que incluye sus creencias religiosas y espirituales, que son altamente valoradas por los drogodependientes y los operadores de las comunidades terapéuticas como factores que promueven el cambio (logro de objetivos), siendo una contradicción que en los protocolos y guías clínicas basados en los PBE excluyan el uso técnicas y actividades espirituales que no tengan fundamento científico.

Por ello, en el caso de las drogodependencias, los psicólogos clínicos que laboran en instituciones usan estos protocolos y manuales con flexibilidad para orientar sus acciones de evaluación, diagnóstico e intervención, pero sin dejar de lado los conocimientos, aptitudes y actitudes que aprendieron y desarrollaron desde la formación académica en la universidad (pregrado, postgrado y educación continua), así como desde la experiencia en el trabajo con los consumidores de SPA, en diversas instituciones, que siguen diversos modelos de intervención. Además, resaltamos el valor que tiene el saber empírico sobre las drogas que poseen algunos psicólogos, pues de forma semejante a los operadores de comunidad terapéutica, este saber facilita la identificación de los usuarios y por ende promueve el establecimiento de la relación terapéutica y la comunicación, al tiempo que permite que el terapeuta pueda tener una compresión empática que le permita ponerse en los zapatos del otro. 
En síntesis, los psicólogos clínicos no reducen sus acciones a lo que sugieren los manuales, guías y protocolos, pues además cuentan con otros modelos teóricos y otras metodologías que articulan adecuadamente, pues tratan de que el cumplimiento de dichos estándares no afecte negativamente la relación terapéutica, siendo indispensable que los psicólogos mantengan una actitud clínica, un interés por el otro y se muestren empáticos, pero también neutrales y con adecuado manejo de la autoridad, de modo que se mantenga un ambiente de rapport que facilite el vencimiento de las resistencias de los pacientes, pues la alianza terapéutica que crean con estos sujetos promueve la autorreflexión y la aceptación de los cuestionamientos, devoluciones e interpretaciones de los psicoterapeutas, de forma semejante a lo que sucede en la relación entre los miembros de las comunidades terapéuticas, las cuales desde sus inicios resaltaban el valor del vínculo, de la relación comunitaria, para la rehabilitación de los drogadictos, factor que en los modelos clínicos de tratamiento institucional no tiene el mismo valor que las técnicas de psicoterapia basadas en evidencia científica, aun cuando la historia muestra la evidencia de la efectividad de los procedimientos creados en tales comunidades, a partir de ideologías religiosas, que sin embargo, no deberían ser concebidas como prácticas no científicas y por ende desvalorizadas o prohibidas, por no proceder de investigaciones que demuestren tal eficacia. Recordamos entonces que los grandes psiquiatras y psicólogos clínicos (científicos) consideran que la relación terapéutica es la esencia de la clínica, pues permite que se desarrolle una "experiencia emocional correctiva."

\section{References}

American Psychological Association Presidential Task Force on Evidence-Based Practice, Washington DC, US (2006, May-Jun). Evidence-based practice in psychology. American Psychologist, 61(4), 271-285. http://dx.doi.org/10.1037/0003-066X.61.4.271

Alexander, F., \& French, T. (1965). Terapéutica psicoanalítica. Principios y aplicación. Paidos

Allen, J. P. y Kadden, R. M. (1995). Matching clients to alcohol treatment. En R. K. Hester \& W. R. Miller (Eds.). Handbook of alcoholism treatment approaches: Effective alternatives (2nd. ed., pp. 278-291). Allyn and Bacon.

Arango, A., \& Moreno, M. (2009). Más allá de la relación terapéutica: Un recorrido histórico y teórico. Acta Colombiana de Psicología, 12(2), 135-145. https://bit.ly/3eIhz2w

Beck, A., Rusch, J., Shaw, B., \& Emery, G. (2012). Terapia cognitiva de la depresión. Descleé de Brouwer.

Becoña, E., \& Cortés, M. (2011). Manual de adicciones para psicólogos especialista en psicología clínica en formación. Sociodrogalcohol. https://bit.ly/3coVsN0

Braunstein, N., Pasternac, M., Benedito, G., \& Saal, F. (2013). Psicología: Ideología y ciencia. Siglo XXI.

Brenstein, D., \& Nietzel M. (2011). Introducción a la psicología clínica. McGraw-Hill.

Bruner, J. (2009). Realidad mental y mundos posibles. Los actos de la imaginación que dan sentido a la experiencia. Cedisa.

Callahan, J., Heath, C., Aubuchon-Endsley, N., Collins Jr., F. \& Herbert, G. (2013, Dec). Enhancing information pertaining to client characteristics to facilitate evidence-based practice. Journal of Clinical Psychology, 69(12), 1239-1249. https://doi.org/10.1002/jclp.21995

Canguilhem, G. (2014). ¿Qué es la psicología? https://bit.ly/2B2RJHT

Casari, L., Ison, M., Albanesi, S., \& Maristany, M. (2017). Funciones del estilo personal del terapeuta en profesionales del campo de las adicciones. Pensamiento Psicológico, 15(1). 7-17. https://doi.org/10.11144/Javerianacali.PPSI15-1.FEPT

Castaño, G., Restrepo, S., \& Uribe, N. (2014). Agresividad, consumo de drogas y "barras 
bravas" en el fútbol. Revista Virtual Universidad Católica del Norte, 41, 79-95. https://bit.ly/3fY8rXQ

Chacón, S. (2016). Prólogo. En C. Rojas (Ed.), Drogas: Interpretaciones y abordajes desde la psicología (pp. 15-18). Universidad Católica de Maule.

Colegio Colombiano de Psicólogos (COLPSIC). (2014). Perfil y competencias del psicólogo en Colombia, en el contexto de la salud.

Cormier, H. W. \& Cormier, L. S. (1994). Estrategia de entrevista para terapeutas. Desclée de Brouwer.

Corominas, D., \& García, I. (2014). Alianza terapéutica y adherencia a tratamientos de drogodependencia: Un estudio en usuarios de centros de atención de la intercomuna Concepción - Talcahuano. Revista Perspectivas, 25, 143-166. https://doi.org/10.29344/07171714.25.422

Cortés, M., Fernández, S., García, B., Martínez, V., \& Sierra, R. (2018). Intervenciones psicológicas basadas en la evidencia en trastornos adictivos. En C. Pereiro \& J. Fernández (Eds.), Guía de adicciones para especialistas en formación (pp. 389-437). Sociodrogalcohol.

Daset, L., \& Cracco, C. (2013). Psicología basada en la evidencia: algunas cuestiones básicas y una aproximación a través de una revisión bibliográfica sistemática. Psicológicas, 7(2), 209-220. https://bit.ly/3eJW01c

De Castro, A., \& García, G. (2017). Psicología clínica fundamentos existenciales. Universidad del Norte.

DuPont, R. L., Compton, W. M., \& McLellan, A. T. (2015). Five-year recovery: A new standard for assessing effectiveness of substance use disorder treatment. Journal of Substance Abuse Treatment, 58, 1-5. https://doi:10.1016/j.jsat.2015.06.024

Durán, N., Restrepo, D., Salazar, C., Sierra, A., \& Schnitter, M. (2007). Historia paralela de la psicología clínica: Un rastreo teórico-histórico. Informes Psicológicos, 9(9), 135-148. https://bit.ly/30bOQ27

Echeburúa, E., Salaberría, K., de Corral, P., \& Polo, R. (2010). Terapias psicológicas basadas en la evidencia: Limitaciones y retos de futuro. Revista Argentina de Clínica Psicológica, 19(3), 247-256. https://bit.ly/2XNYoxg

Ediomo-Ubong, E., \& Gboyega, E. (2019). Multiple barriers to utilization of drug abuse treatment by female street sex workers in Nigeria. Journal of Psychoactive Drugs, 51(4), 383-390. https://doi:10.1080/02791072.2019.1605103

Etchevers, M., Simkin, H., Putrino, N., Giusti, S., \& Helmich, N., (2014). Relación terapéutica: Estudio en población de psicólogos clínicos. Anuario de Investigaciones, 21, 23-30. https://bit.ly/2Mj5Efl

Fiorini, H. (1992). Teorías y técnicas de psicoterapia. Nueva Visión

Freud, S. (2007). Consejos al médico en el tratamiento psicoanalítico. Amorrortu. (trabajo original publicado 1912).

Gadamer, H. (2017). El estado oculto de la salud. Gedisa.

Goti, M. (2003). La comunidad terapéutica (Breve repaso de su historia y algunas definiciones del modelo). Las drogas.info. https://bit.ly/3c7RY10

Goti, M. (2009). La comunidad terapéutica: Un desafío a la droga. Fundación Hogares Claret.

Hai, A. H., Franklin, C., Park, S., DiNitto, D. M., \& Aurelio, N. (2019). The efficacy of spiritual/religious interventions for substance use problems: A systematic review and meta-analysis of randomized controlled trials. Drug and Alcohol Dependence, 202, 134-148. https://doi:10.1016/j.drugalcdep.2019.04.045

Hayes, S., Barlow, D. \& Nelson-Gray, R. (1999). The practitioner: Research and scientist accountability in the age of managed care. Allyn \& Bacon.

Hayes, S., Long, D., Levin, M. \& Follette, W. (2013, Nov). Treatment development: Can we 
find a better way? Clinical Psychology Review, 33(7), 870-882. https://doi.org/10.1016/j.cpr.2012.09.009

Haynes, R. B., Sackett, D. L., Gray, J. M., Cook, D. J., \& Guyatt, G. H. (1996). Transferring evidence from research into practice: The role of clinical care research evidence in clinical decisions. ACP Journal Club, A14-A16. http://dx.doi.org/10.1136/ebm.1996.1.196

Hernández, R., Fernández, C., \& Baptista, M. (2014). Metodología de la investigación. McGraw Hill/Interamericana de Editores.

Iudici, A., Castelnuovo, G., \& Faccio, E. (2015). New drugs and polydrug use: Implications for clinical psychology. Front Psychol. 6, 267. https://doi:10.3389/fpsyg.2015.00267

Janesick, V. (1998). Stretching exercises for quailitative researchers. Sage

Kooyman, M. (1996). La comunidad terapéutica para drogodependientes. Ediciones el Mensajero.

Lacan, J. (2009). Escritos 1. Variantes de la cura tipo. Siglo XXI

Laing, R. D. (2015). El yo dividido. Un estudio sobre la salud y la enfermedad. Fondo de Cultura Económica.

Lam, R., Pérez, M., Hernández, P., \& Milanés, M. (2002). Medicina basada en la evidencia. Revista Cubana de Hematología, Inmunología y Hemoterapia, 18(3). https://bit.ly/3ckOf0g

Lambert, M. J., \& Barley, D. E. (2001). Research summary on the therapeutic relationship and psychotherapy outcome. Psychotherapy: Theory, Research, Practice, Training, 38(4), 357-361. https://bit.ly/3dCW6bb

Linn, S., \& Garsken, J. (1993). Psicoterapias contemporáneas: Modelos y métodos. Desclée de Brouwer.

Lowman, R. L. (2012, Sept). The scientist-practitioner consulting psychologist. Consulting Psychology Journal, Practice \& Research, 64(3), 151-156. http://dx.doi.org/10.1037/a0030365

Martínez, K., \& Medina-Mora, M. (2013). Transferencia tecnológica en el área de adicciones: El programa de intervención breve para adolescentes, retos y perspectivas. Salud Mental, 36(6), 505-512. https://bit.ly/2PSeqTr

Martínez-Taboas, A. (2014). Prácticas psicológicas basadas en la evidencia: Beneficios y retos para Latinoamérica. Revista Costarricense de Psicología, 33(2), 63-78. https://bit.ly/3eIIBGY

Mayor, E., Noval, C., Cepedello S., \& Prieto, A. (2018). Historia clínica en adicciones. En C. Pereiro \& J. Fernández (Ed.), Guía de adicciones para especialistas en formación (pp. 21-40). Sociodrogalcohol.

Ministerio de salud (MINSALUD) \& Oficina de las Naciones Unidas Contra la Droga y el Delito (UNODC). (2016). Modelo de atención integral para trastornos por uso de sustancias psicoactivas en Colombia. https://bit.ly/3c6nqgi

National Institute on Drug Abuse. (2018). Las drogas, el cerebro y la conducta: La ciencia de la adicción. U. S. Department of Health and Human Services. https://bit.ly/2XA3w7V

Organización Mundial de la Salud. (2004). La dependencia de sustancias es tratable, sostiene un informe de expertos en neurociencias. World Health Organization. https://bit.ly/2ZD27Ab

Pacheco, T., Ayme, M., \& Martínez, K. (2013). El arte de ser terapeuta. ¿Qué hace efectiva una intervención en el consumo de drogas? Enseñanza e Investigación en Psicología, 19(1), 199-217. https://bit.ly/3cqXZG8

Perls, P. (2016). Enfoque gestáltico y testimonios de terapia. Cuatro Vientos.

Piaget, J. (1983). Estudios sociológicos. Editorial Ariel.

Quant, D., \& Trujillo, S. (2014). Psicología clínica basada en la evidencia y su impacto en la 
formación profesional, la investigación y la práctica clínica. Revista Costarricense de Psicología, 33(2), 123-136. https://bit.ly/2zSOyCj

Resnick, J. H. (1991). Finally, a definition of clinical psychology: A message from the President, Division 12. The Clinical Psychologist, 44, 3-11.

Rey, C., \& Guerrero, S. (2012). Tendencias de proyectos de investigación en psicología clínica en Colombia. Revista Psicología Desde el Caribe, 1(29), 176-204. https://bit.ly/3gOe38n

Rogers, C. (2010). Psicoterapia centrada en el cliente práctica e implicaciones teóricas. Paidós

Sackett, D. L., Rosenberg, W. M., Gray, J. A., Haynes, R. B., \& Richardson, W. S. (1996). Evidence-based medicine: What it is and what it isn't. British Medical Journal, 312, 71-72. https://doi.org/10.1136/bmj.312.7023.71

Trull, E. J., \& Phares, T. J. (2003). Psicología clínica: Conceptos, métodos y aspectos prácticos de la profesión. Thomson.

Wilson, G. T. \& O’Leary, K. D. (1980). Principles of behaviortherapy. Prentice-Hall.

Winnicott, D. (2013). Realidad y juego. Gedisa

Yalom (2010) Psicoterapia existencial. Herder

Zhang, H. H., Tan, L. X., Hao, W., \& Deng, Q. J. (2017). Evaluation of a community-based integrated heroin addiction treatment model in Chinese patients. Oncotarget, 8(33), 54046-54053. https://doi.org/10.18632/oncotarget.18681 


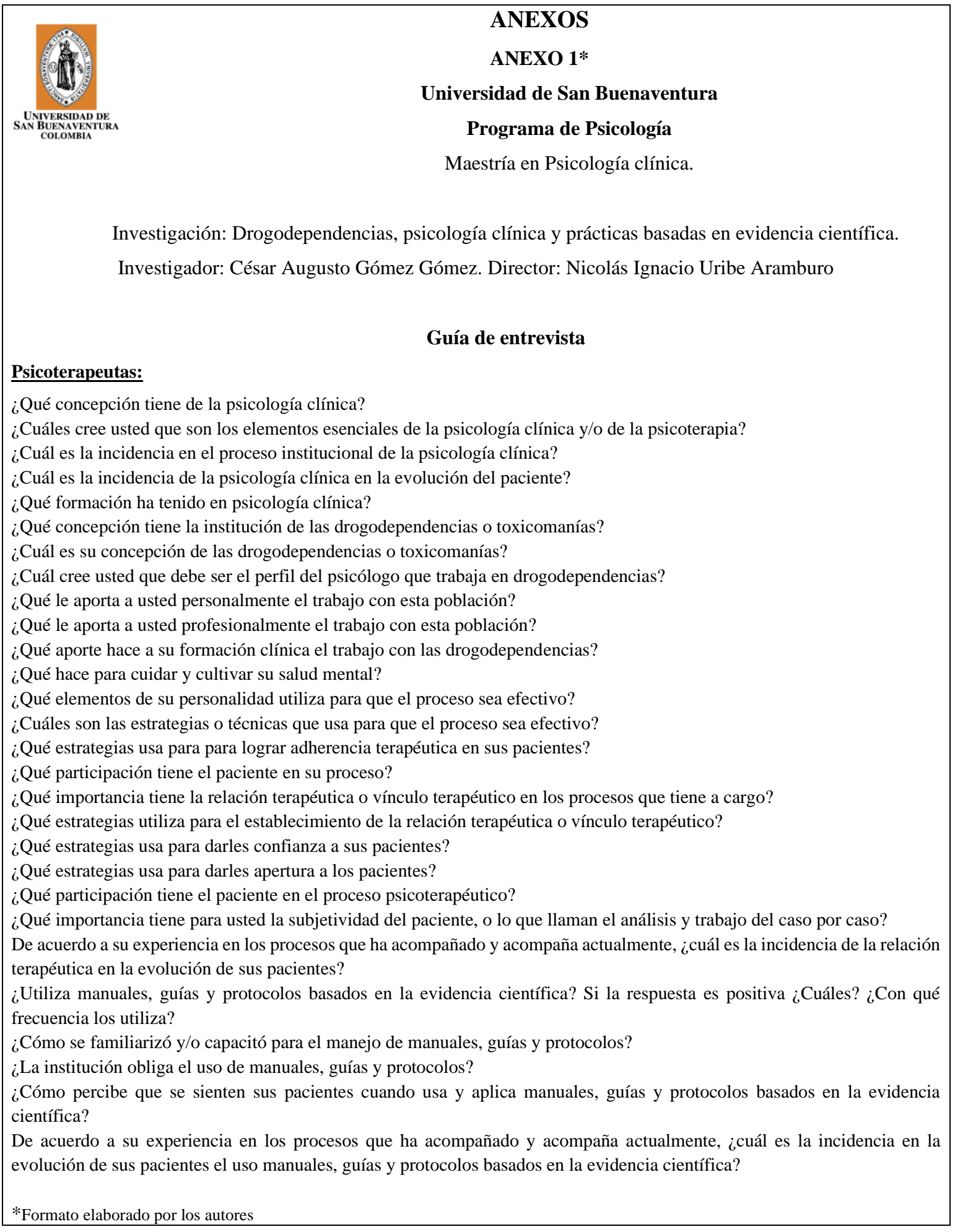




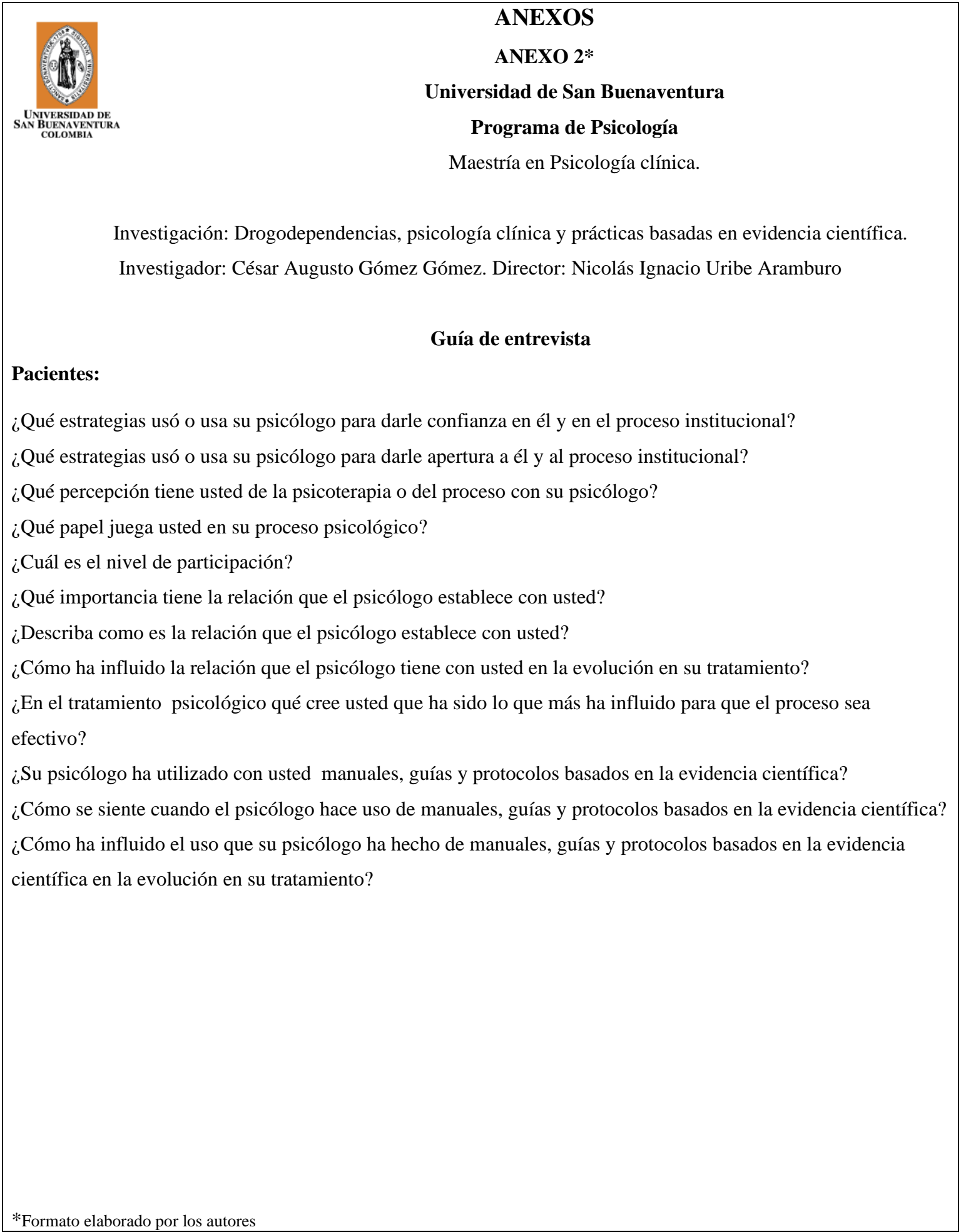




\section{Author Note}

César Augusto Gómez Gómez es Psicólogo Universidad Católica de Oriente (UCO), Especialista en Farmacodependencia Fundación Universitaria Luis Amigó (FUNLAM), Magíster en psicología clínica Universidad de San Buenaventura (USB), Facultad de Ciencias Sociales, Programa Psicología, Docente de cátedra y asesor de prácticas profesionales, (UCO), Sector 3 carrera $46 \mathrm{~N}^{\circ} 40$ B 50 Rionegro, Colombia. cesar.gomez8062@ soyuco.edu.co, móvil 3113660092. Enlace ORCID id: 0000-0001-5733-3189. Por favor, envíe correspondencia directa a cesar.gomez8062@ soyuco.edu.co.

Nicolás Ignacio Uribe Aramburo es Psicoanalista, Magíster en investigación psicoanalítica Universidad de Antioquia (U.deA.). Docente Asociado de tiempo completo, Universidad de San Buenaventura (USB), miembro de los grupos de investigación: "Estudios clínicos y sociales en psicología" (USB) y "Estudios sobre juventud" (U.deA.), coordinador de la línea de adicciones y del semillero de investigación Psicoactiva (USB). Por favor, envíe correspondencia directa a nicolas.uribe@usbmed.edu.co.

Copyright 2021: Cesar Augusto Gómez Gómez, Nicolás Ignacio Uribe Aramburo, and Nova Southeastern University.

\section{Article Citation}

Gómez, C. A. G., \& Uribe, N. I. A. (2021). Análisis del tratamiento para drogodependencias en dos instituciones de Medellín. Integración de elementos esenciales de la clínica y prácticas. The Qualitative Report, 26(10), 2981-3013. https://doi.org/10.46743/2160$3715 / 2021.5057$ 